\title{
Una pena sepulcral en favor de la res publica Aiungitanorum
}

\author{
R. LÓPEz MELERo *-A. U. STYLOW **
}

a Géza Alföldy

en su 60 aniversario

Hispania Uiterior Baetica era una de las provincias del Imperio más ricas en ciudades 1, aunque no las tenía uniformemente distribuidas: mientras en el norte, en la Baeturia de los túrdulos y de los célticos, no era infrecuente que distaran $50 \mathrm{~km}$, o incluso más, una de otra, se amontonaban en cambio en el fértil valle del Betis, y especialmente en el accidentado borde norte del sistema Subbético, es decir, en el sur de las

* Departamento de Prehistoria e Historia Antigua de la UNED, Madrid. Munich.

* Kommission für Alte Geschichte und Epigraphik des Deutschen Archäologischen Instituts,

El presente trabajo es la versión española del recientemente aparecido en Chiron 25, 1995, 357-386 como «Epigraphische Miszellen aus der Provinz Jaén. 1. Eine Grabbuße zugunsten der Res publica Aiungitanorum". Sucesivos artículos de esta serie se encuentran publicados en CPUG 16-17, 1991-1992 [1995] y en AAC 6, 1995, 217-237. Bibliografia que se cita abreviada: CILA Jaén = González Román, C.-MANGas ManjarRes, J., Corpus de Inscripciones Latinas de Andalucia III. Jaén, 2 vol., Sevilla 1991 [1993]; DE VISSCHER = DE VISSCHER, F., Le droit des tombeaux romains, Milán 1963; GIORGI = GIORGI, G., Le multe sepolcrali in diritto romano, Bolonia 1910; KASER = KASER, M. "Zum römischen Grabrecht", ZRG 95, 1978, 15-92; LAZZAAINI 1984 = LAZZARINI, S., "Sepulcrum familiare" e "ius mortuum inferendi"”, en Studi in onore di Arnaldo Biscardi V, Milán, 1984, 217-237; LAZZARINI 1991 = IDEM, Sepulcro familiare. Un'indagine epigrafico-giuridica, Padua 1991; RossI = RossI, A.-M., "Ricerche sulle multe sepolcrali romane", RSA 5, 1975, 111-159; STYLOW 1983 = STYLOW, A.U., "Inscripciones latinas del sur de la provincia de Córdoba", Gerión 1, 1983, 267-303, STYLOW 1995 = IDEM, "Los inicios de la epigrafía latina en la Bética. El ejemplo de la epigrafía funeraria", en Roma y el nacimiento de la cultura epigráfica en Occidente (1992), Zaragoza 1995, 219-238. Las siglas utilizadas para titulos de revista son las de L'Année Philologique. Estando en pruebas esta versión castellana del trabajo, tuvimos noticia de una publicación de esta inscripción por C. GONZÁLEZ ROMÁN en Florentia lliberritana 6, 1995, 210-213.

1 Estrabón $(3,2,1)$ cuenta doscientas ciudades; dos generaciones más tarde habla Plinio (NH $3,7)$ de ciento setenta y cinco. 
actuales provincias de Jaén y Córdoba y en el sureste de Sevilla. Cuando, en esta zona, algún hallazgo epigráfico feliz nos da a conocer un nuevo municipio, nos vemos obligados a volver a reflexionar sobre algunos planteamientos tradicionales y criterios metodológicos de las respectivas localizaciones. Puesto que la nueva inscripción es, por añadidura, el primer testimonio hispano de una pena sepulcral -un instrumento jurídico conocido sobre todo de Italia y de Asia Menor-, resulta obligado revisar el lugar que ocupan esas penas dentro del derecho romano, y, desde luego, su aplicación; sobre todo, porque algunos testimonios de tal procedimiento no habían sido tomados hasta ahora, a nuestro juicio, en la debida consideración.

La inscripción se encuentra en una estela que salió a la luz en agosto de 1993 en el cortijo «El Estanquillo», sito a un kilómetro aproximadamente al suroeste de Alcaudete (Jaén), cuando se realizaban labores agrícolas, y fue cedida poco después por el propietario de la finca al Museo Provincial de Jaén (no invent. 2844). El día 14 de septiembre del mismo año informaba ya del hallazgo el arqueólogo provincial $\mathrm{N}$. Zafra de la Torre en un artículo del Suplemento del diario "Jaén" editado con motivo de la fiesta patronal de Alcaudete ${ }^{2}$, dando una lectura provisional de la inscripción. Algunos meses después pudimos estudiar la pieza en los almacenes del Museo ${ }^{3}$.

La estela (lám.1) es de caliza micrítica gris oscura, compacta y de grano fino, una piedra que aparece en numerosos lugares del sistema Subbético, pero también en Sierra Morena. En época romana era ésa la piedra de construcción preferida en la Bética, aunque también se utilizaba gustosamente para inscripciones, e incluso, cuando en la segunda mitad del s. I d.C. aumentó a este efecto el uso del mármol, se siguió empleando, sobre todo para los soportes de mayor tamaño. Tenía originariamente un remate superior casi semicircular, que en su mayor parte fue recortado más tarde, es de suponer que para su reutilización como umbral de una

2 Agradecemos a D. Fco. Machado Uliarte, de Alcaudete, el habernos dado a conocer esa publicación.

3 Agradecemos a la Consejeria de Cultura y Medio Ambiente de la Junta de Andalucía el correspondiente permiso para el estudio de la pieza, así como al director del Museo de Jaén, J. L. Chicharro Chamorro, y al conservador del mismo, P. Molina Poyatos, la amable acogida y el apoyo prestado durante nuestro trabajo. 


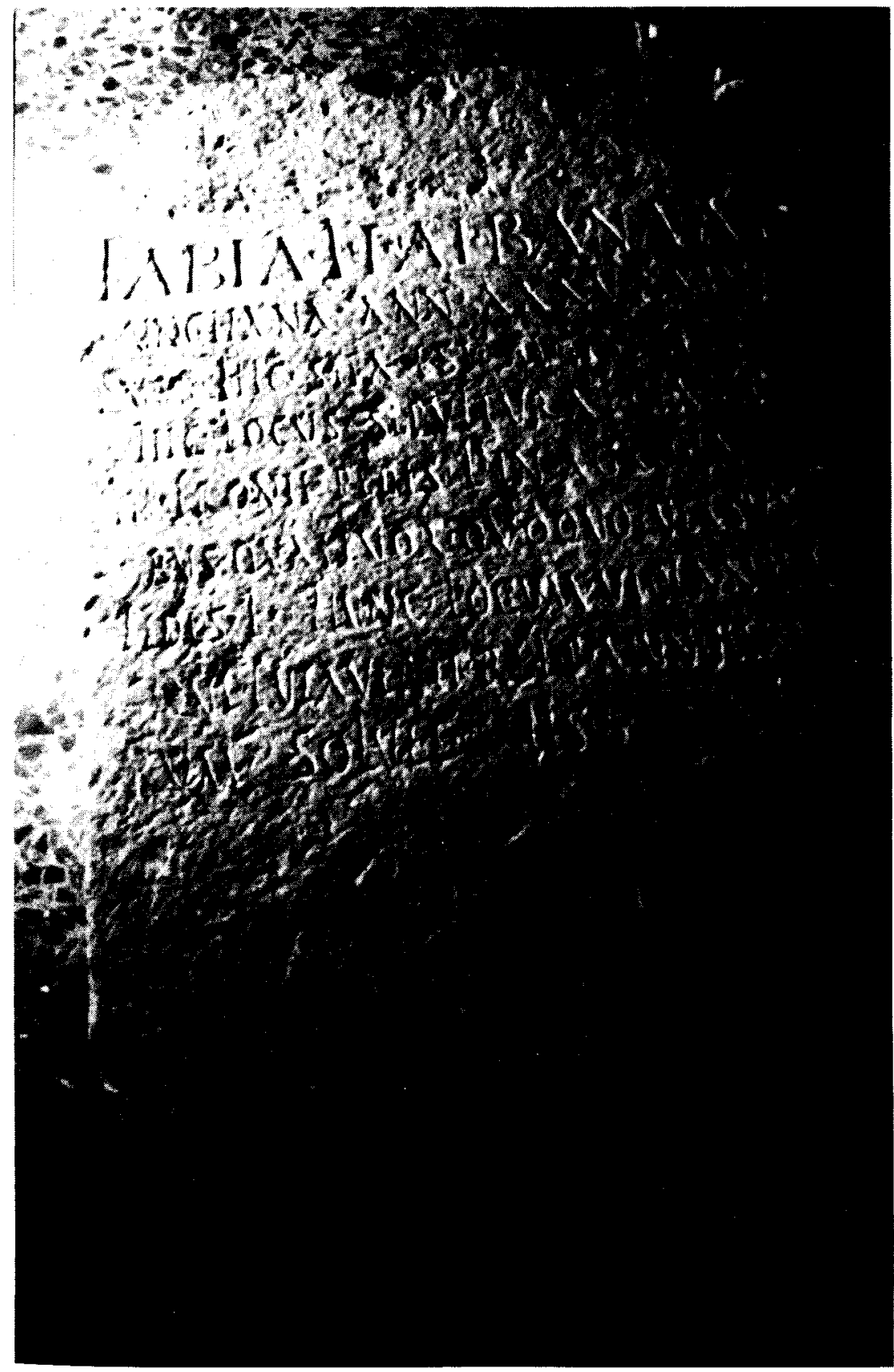

Lám. 1. Estela de Alcaudete. 
puerta, circunstancia ésta que cabe deducir del agujero de gozne conservado al final de la línea quinta — sólo la mitad de él se encuentra en esta piedra-, así como de la abrasión observable en la parte derecha de las líneas 1-3, que sería debida al prolongado pisoteo. Queda claro con ello que la estela no ha sido encontrada in situ, aun cuando Zafra de la Torre hable, en el mencionado artículo, de materiales de construcción romanos (probablemente ladrillos) y cerámica, observados por el lugar de hallazgo, que le llevan a postular la existencia de una necrópolis. De hecho, podría tratarse igualmente de los restos de una villa romana, aunque, por otra parte, los testigos oculares del hallazgo, buenos conocedores de la zona, a quienes hemos podido entrevistar, afirman que carece de restos romanos. En cualquier caso, la estela no puede haber sido hallada muy lejos de su lugar de ubicación original, puesto que su gran peso y la abundancia de piedra en la zona hacen poco verosímil cualquier desplazamiento desde una distancia grande.

La parte inferior de la estela está rota; su altura actual es de $108 \mathrm{~cm}$, su ancho de $59 \mathrm{~cm}$ y su grueso de $22-24 \mathrm{~cm}$. Pertenece, por lo tanto, a un tipo de estelas - redondeadas por arriba, pero, por lo demás, totalmente carentes de ornamentación- de extraordinaria anchura y grosor, de la que se conocen numerosos ejemplares procedentes del borde septentrional del sistema Subbético y de la Campiña de Jaén y Córdoba hasta la provincia de Sevilla, aunque allí aparecen con más frecuencia los campos epigráficos rebajados.

La parte posterior y los costados de la estela están someramente desbastados; la cara anterior, la del área epigráfica, ha sido, por el contrario, alisada, pero no por igual, sino dejando muchas protuberancias y concavidades. Que ése era el estado de la pieza cuando se grabó, lo atestigua el hecho de que la inscripción haya ido acomodándose a tales irregularidades (de ahí las obligadas distorsiones del comienzo de las líneas 6 y 7), así como algunas letras incisas en las concavidades (la $S$ de SEPVLTVRAE en la línea 4, o la $V$ de LOCVM en la línea 7). La razón de ello no debería buscarse en una descuidada preparación de esta pieza, pues, en contra de tal posibilidad, no sólo tenemos la propia escritura, que muestra un elevado nivel técnico (aunque siempre se podría pensar en dos talleres distintos, que hubieran sido responsables, respectivamente, de la preparación y de la inscripción), y la existencia de estelas preparadas y grabadas del mismo modo en el entorno próximo ${ }^{4}$, sino también el fenómeno

4 Ex. gr. CILA Jaén 461 (TUCci). 
repetidamente observado en la Bética de que, hasta bien entrado el s. II, en lápidas, por lo demás trabajadas con gran cuidado y regularidad, se dejan las huellas del cincel denticulado, para asi formar un fondo esgrafiado mate, donde resalta mucho más el bisel liso, a veces pulido, de las letras ${ }^{5}$.

Un similar efecto manierista produce también la ordinatio de la escritura, que se conserva completa hasta unos pequeños desconchones del borde derecho y hasta el ya mencionado agujero del gozne: las líneas han sido manifiestamente realizadas con guía, están muy espaciadas, y todas las pares (excepto la 8 ) van sangradas al principio y al final, de modo que producen la impresión óptica de un epigrama compuesto en dísticos elegíacos. Ese esquema formal no tiene correspondencia alguna con el contenido, al cual se acomoda la inscripción de un modo totalmente mecánico. El uso de una cabecera escrita en capitalis quadrata (o una escritura parecida), seguida del grueso del texto en scriptura libraria, aparece con frecuencia a partir del s. Il en la Bética, en inscripciones honoríficas lo mismo que funerarias 6 ; aunque, de todas formas, lo que se encuentra allí por regla general es la libraria alta y estrecha, que parece como pintada con pincel, tan característica de las inscripciones béticas y africanas. Aquí, por el contrario, han sido combinadas de modo sorprendente las formas sencillas de la scriptura communis con las líneas curvas y los refuerzos destacados de la libraria, logrando así una caligrafía graciosa, donde una serie de letras y trazos más altos - sobre todo I, $H$ (aquí el primer trazo vertical) y $L$, 10 mismo que, en general, en los comienzos de palabra - viene a romper la monotonía. Después de la línea inicial, destacada por el tipo de letra y por su tamaño $(5 \mathrm{~cm})$, prosigue el texto con letras de $3 \mathrm{~cm}$ de alto, para terminar con una línea de letras de nuevo más altas, y, por lo demás, más espaciadas. La pequeña interpunción triangular se pone regularmente. El texto reza (lám. 2):

${ }^{5}$ Cf. la inscripción (¿de Tiberio?) CIL $11^{2} / 7,254$ (con tab. 9, fig. 6), o bien el epigrafe de la Aqua Nova Domitiana Augusta (CIL II/2/7, 220 (con tab. 7, fig. 3)), ambas de Corduba.

6 Ex. gr., en las inscripciones cordubenses de los flámines provinciales del 152 y el 191 d. C. (CIL $\|^{2} / 7,291$ y 293 resp.); cf. también los epígrafes funerarios $\mathrm{CIL} \|^{2} / 7,493$ y 508 . Uno de los ejemplos más tempranos de ese estilo es una inscripción honorifica de Singilia Barba (HEp 2, 1990, 469) del año 109. Distinto es el caso, con correspondencia de forma y contenido, de las (tempranas) inscripciones en las que se combinan unas letras de mayor altura en la línea del nombre y un epigrama sepulcral en letra más pequeña (ex. gr. CIL $11^{2} / 7,199$ y 498). 


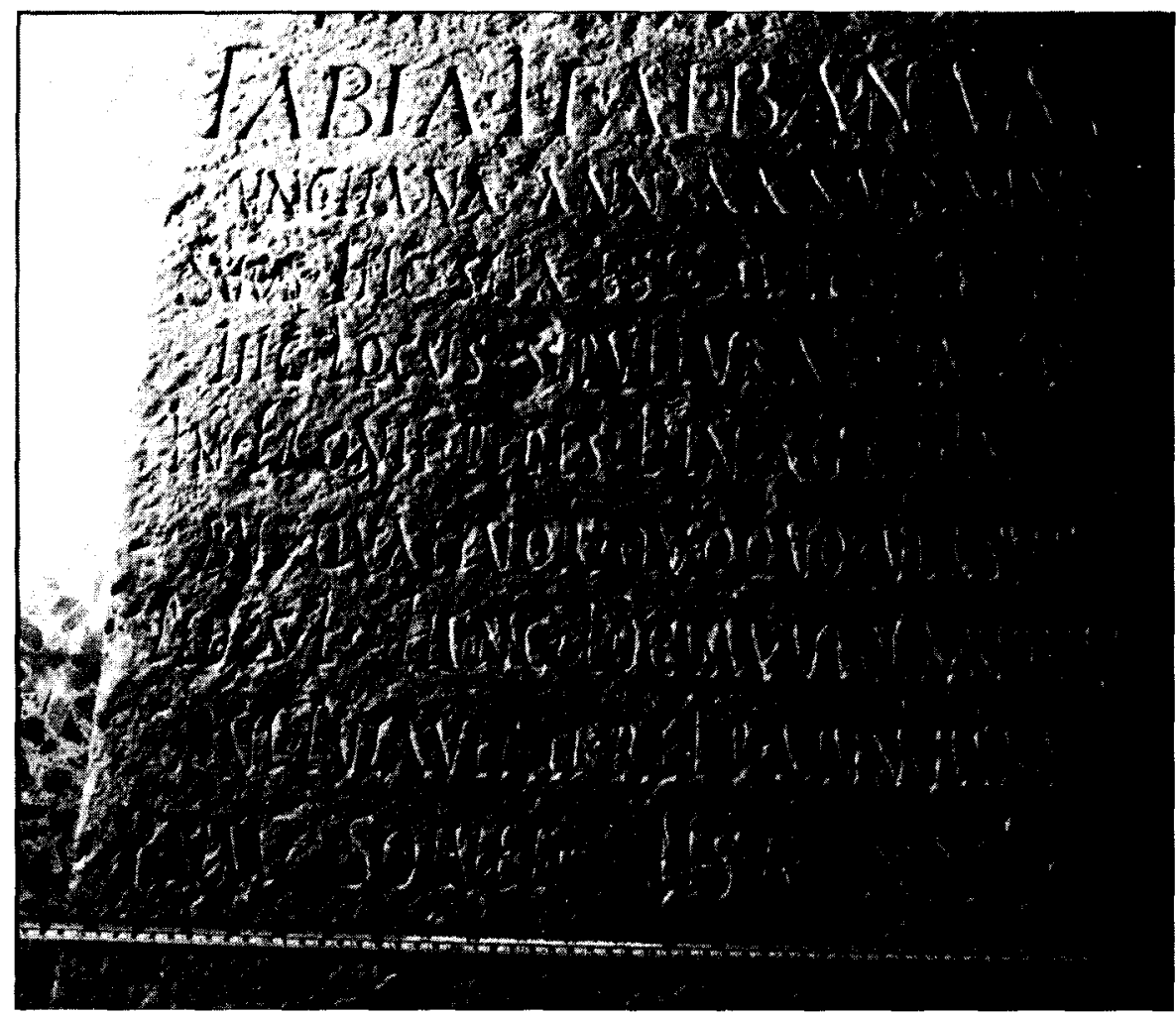

Lám. 2. Inscripción de la estela de Alcaudete.

Fabia・L(uci)•f(ilia) $\cdot A / b a n a \bullet A i-$

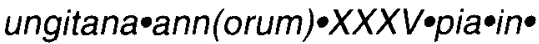

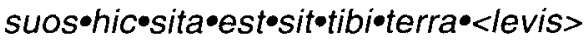
hic $/$ ocus•sepulturae•habet•

5 in॰fronte $\bullet$ pedes $\llcorner\bullet$ in $\bullet$ agro $/ a t e[r i]-$ bus`quattuorøquoquo'versus• pedes $L \bullet$ hunc $\bullet$ locum•violandum qui॰putaveriterei॰p(ublicae)-Aiungitanorum•solvet•(sestertium) $\bullet X X($ scil. milia) $[n(u m m u m) ?]$

3 LEVIS ha caido por un descuido del lapicida. - 9 HS en la piedra. XX con línea sobrepuesta. En vista de la cuidada ordinatio, se puede conjeturar la pérdida de una letra al final; en lugar de n(ummum), sería también posible $m$ (ilia). 
El texto se articula en tres secciones. La primera parte (líneas 1-3) nos da el nombre, el origen y la edad de la difunta, y termina con unas fórmulas sepulcrales que se encuentran en la Bética en esa combinación desde la época de Tiberio hasta aproximadamente el final del dominio de los Severos. La inscriptio plena de las fórmulas es característica sobre todo del comienzo de ese largo período, pero vuelve a aparecer - como aquíen tiempos de los Antoninos; de todas formas, hay que constatar que nuestra inscripción evita las abreviaturas en general. También la forma pia in suos, en lugar de la que es frecuente en la Bética, pia in suis, lo mismo que la abreviatura ann(orum), en lugar de an(norum), apuntan al s. II, por más que aparezcan ya antes en forma aislada ${ }^{7}$. El nombre de la difunta -en nominativo, como es normal en Hispania- resulta poco ilustrativo: Fabia, uno de los gentilicios hispanos más frecuentes ${ }^{8}$, se concentra en la provincia de Jaén, en las ciudades situadas en el borde septentrional del sistema Subbético ${ }^{9}$, es decir, en los alrededores del lugar de hallazgo de la estela. Albanus es frecuente en toda la parte meridional de la Península (con pocas excepciones), en territorios fuertemente romanizados, si bien hasta ahora se había encontrado sólo como masculino ${ }^{10}$. El topónimo Aiungi (sobre cuyo status y localización vide cap. V), que se deduce de la forma adjetival Aiungitanus (líneas 1/2 y 8/9), no estaba atestiguado hasta ahora - al menos tal cual. Tenemos, sin embargo, en la relación de los asistentes al concilio de Elvira, celebrado a comienzos del s. IV, un presbítero - Barbatus- procedente de una ciudad de cuyo nombre parecen contener los manuscritos las variantes Adiungi/Aduingi ${ }^{11}$. Ahora bien, la primera de tales variantes po-

Sobre esos criterios de datación, véase STYLow 1995, 222-223.

8 Después de las investigaciones de KNAPP, R.C. (AncSoc 9, 1978,187-122) y DYSON, L. (AncSoc12, 1980/81, 257-299) contamos ahora con las utilisimas estadísticas de ABASCAL PALAzÓN, J.M. (Los nombres personales en las inscripciones latinas de Hispania, Murcia $1994,29)$.

9 CILA Jaén 22, 23 y 34 (Aurgi); 279, 282, 286 y 290 (Mentesa); 343 (Ossigi); 455 (Tucci); cf. CIL II 1601 (Fuente Alhama, término de Luque, al oeste de Alcaudete).

10 Los datos, en ABASCAL, O.c. 264.

1 La lista de los presbiteros asistentes al concilio iliberritano sólo ha sido transmitida por una de las cuatro familias de manuscritos que componen el stemma de la Hispana. De esa familia -rama catalana de la Recensión Vulgata de la Hispana- se conservan el Códice Gerundense (G), supuestamente procedente de Gerona y datado a comienzos del $s$. IX, y el Códice de Urgel (U), con procedencia atribuida a esta última ciudad y datación de finales del s. XI, y del cual no sería el códice gerundense predecesor sino colateral muy próximo (cf. La Colección Canónica Hispana, t. I. Estudio, G. MARTinez Díez, Madrid 1966, 139-141). Según la colación de G. Martinez 
dría ser el resultado de una adulteración del topónimo indígena Aiungi, producida en algún punto de la tradición manuscrita por interferencia de una palabra latina conocida ${ }^{12}, y$, a su vez, esa posible documentación epigráfica de su forma genuina, con que contaría así Adiungi, la convertiría en lectio melior, frente a Aduingi, carente de cualquier referencia de identificación como nombre de lugar.

Por lo demás, el topónimo encaja muy bien en el conocido grupo que lleva ese sufijo -gi, o bien -ci, con el que se han formado también muchos antropónimos ibéricos (sin que por ello los topónimos deban ser considerados como derivados de esos antropónimos): así - para mencionar algunos ejemplos de las proximidades de Alcaudete-, Aurgi (Jaén), de aur-; Iliturgi (en Mengíbar), de ilti+turi-; Onigi (al sur de Puente Genil), de uni(n)-; o bien, Sosontigi (al lado de Alcaudete, vide cap. V), de sosin- ${ }^{13}$. También aiun- está reiteradamente atestiguado entre los antropónimos ibéricos ${ }^{14}$, por lo que, en definitiva, se adecúa muy bien en el aspecto lingüístico a este territorio.

Diez y F. Rodriguez (o.c. t. IV Concilios Galos. Concilios Hispanos, $1^{\text {a }}$ parte, Madrid 1984, 240), en el manuscrito $U$ se podría leer indistintamente Aduingi (que sería lección clara en el manuscrito G) y Adiungi, lo que se entiende muy bien si consideramos que en la escritura minúscula carolina de esos manuscritos las secuencias uin e iun - representadas ambas básicamente por cinco trazos verticales - apenas se distinguen entre sí, de suerte que, tratándose de palabras, como habría sido el caso del topónimo en cuestión, no reconocibles para el copista, era muy fácil que se produjeran adulteraciones, o bien grafias ambiguas como la que tenemos en el manuscrito U. Por lo tanto, no es posible decidir, en términos paleográficos, cuál de las dos lecciones ha generado la otra, o, lo que es lo mismo, cuál es el topónimo que está detrás de esas grafias. En cuanto a la conjetura Astigi, tan justificadamente ignorada por MARTínez DiEz como incomprensiblemente incorporada al texto en calidad de emendación por J. VIvES (Concilios visigóticos e hispano-romanos, ed. con T. Marín Martinez y G. Martínez Diez), Barcelona-Madrid 1963,1 , sólo cabe decir que el nuevo epigrafe de Alcaudete la deja fuera de juego. En definitiva, no era más que un intento de resolver un caso típico de topónimo indocumentado, por recurso a una supuesta corruptela, que habria hecho desaparecer del textus receptus un topónimo conocido relativamente homógrafo -en este caso, el de una ciudad cuya falta de representación en el concilio podría parecer sorprendente. Ni que decir tiene que, a pesar de la relativa aceptación que ha tenido esa conjetura como tal (vide García VILLADA, Z., Historia Eclesiástica de España, t. I, 1, Madrid 1929, 175; ThOUVENot, E., Essai sur la province romaine de la Bétique, París 1940, 321, y Tovar, A., Iberische Landeskunde, $2^{a}$ parte, Die Völker und die Städte des antiken Hispanien, t. I, Baetica, Baden-Baden 1974, 180), resulta, en cualquier caso, paleográficamente poco feliz, dada la mínima similitud existente entre las secuencias diun (o duin) y sti.

12 En esa relación no faltan topónimos ligeramente adulterados, como el caso de Ategua, que aparece como Ateua, o el de Olauro, que se lee como Alauro.

13 Con ello queda también claro que la variante Sosintigi, transmitida por Plinio NH 3,10 no es más que un doblete sin asimilación.

14 Untermann, J., Monumenta Linguarum Hispanicarum III. Die iberischen Inschriften aus Spanien, Wiesbaden 1990, 209. Agradecemos a J. Untermann su generosa información a ese respecto. 
La segunda parte de la inscripción (líneas 4, 5, 6 y comienzo de la línea 7) contiene los datos de la pedatura sobre las medidas del locus sepulturae, que, en su prolijidad, valdría decir redundancia, carecen de paralelo en Hispania y, teniendo en cuenta la simplicidad del caso, incluso fuera de la Península. Mientras que la anchura, normalmente a 10 largo de un camino, se nos da en la forma usual, con in fronte, la extensión en profundidad (in agro) aparece con una doble referencia al largo y al ancho (lateribus quattuor y quoquo versus), de tal manera que, cuando al fin se menciona la segunda medida, podría surgir incluso la sospecha de que se tratara de un contorno más complicado que el simple cuadrado de cincuenta pies de lado que usualmente se determinaba con la fórmula "(l(ocus)) in fronte $p$ (edes) tot, in agro $p$ (edes) tot", $\circ$, de un modo aún más conciso, como "l(ocus) $q($ uo)q(uo) v(ersus) p(edum) tot ${ }^{15}$.

¿Por qué aquí no? ¿Podría ser que, cuando nuestra estela fue erigida, ya se hubiera rebasado la época en la que era usual en la Bética consignar las medidas del locus en las propias estelas funerarias, o bien en estelas terminales especiales situadas en las esquinas del mismo? La pedatura es de hecho una manifestación claramente delimitada en el tiempo y también en el espacio geográfico. La conocemos en Italia -fuera de Roma, especialmente en el centro y en el norte de la península, con menos frecuencia en el sur ${ }^{16}$-, en la Narbonense y en la Hispania meridional, es decir en el núcleo del Imperio y en las regiones más temprana y profundamente romanizadas ${ }^{17}$. En Hispania, el principal territorio de difusión es la Bética, y aquí, a su vez, el conventus Astigitanus, seguido del Cordubensis, o, lo que es lo mismo, la Campiña de las provincias de Jaén,

15 Lo mismo -y no que se tratara de un área circular- se ha querido expresar probablemente con la inscripción rupestre locus const<itut>us in circum pedes CL (AE 1967, 218) de Torreorgaz (Cáceres), si bien aqui la referencia a un locus sepulturae es un tanto inverosimil.

16 Aqui se trata, prácticamente sin excepción, de necrópolis suburbanas, no de enterramientos en suelo rural, según nos ha indicado amablemente F. X. Espluga Corbalán.

17 Dificilmente podria ser casualidad que tengamos más o menos los mismos límites espaciales (y probablemente también temporales) con respecto a la costumbre de colocar retratosherma con inscripciones: vide PoRtillo, R. - Rodriguez Oliva, P. - StYLow, A.U., «Porträthermen mit Inschrift im römischen Hispanien", MDAl(M) 26, 1985, 185-217, espec. 216-217. En cualquier caso, se ha visto claro después, por nuevos hallazgos, que, en contra de la argumentación antigua, también en Hispania, lo mismo que en el norte de Italia y en la Narbonense, se erigia ese tipo de herma -al margen de su función en el culto del Genius, o, en su caso, de la luno, de los do- 
Córdoba y Sevilla, con el valle del Guadalquivir. En el este, comprende ese territorio también Cástulo, que, como es sabido, incluso después de que Augusto hubiera segregado la Bastetania oriental de la Ulterior Baetica y la hubiera agregado a la Citerior, había conservado sus antiguas vinculaciones con la Bética ${ }^{18}$. Testimonios aislados se encuentran en el oeste del territorio, en el conventus Hispalensis, y en la Lusitania meridional, sobre todo por Mérida, así como en Levante, en Sagunto y Carthago Nova. Cronológicamente, comprende ese fenómeno en Hispania ${ }^{19}$ poco más de un siglo: desde la época augústea, con anterioridad a la cual apenas existió en la Bética una producción epigráfica digna de mención ${ }^{20}$, hasta el final del s. I. Sólo en una pequeña zona del conventus Astigitanus, concretamente en el territorio fronterizo meridional de las provincias de Jaén y Córdoba (es decir, en los alrededores del lugar de hallazgo de nuestra estela), se mantuvo la costumbre algo más de tiempo, puesto que de alli proceden algunas inscripciones funerarias con dos elementos que, por lo general no aparecen combinados en Hispania: por un lado, todavía la pedatura; por otro, ya la dedicación a los Manes ${ }^{21}$, sólo generalizada - después de algunos arranques sin continuidad de la época julioclaudia- a comienzos del s. II, en estrecha relación con la difusión contem-

mini- públicamente como monumento honorífico, y también, según se ve, en las tumbas. Véase por ahora STYLow, A.U., "Más hermas", Anas 2/3, 1989/90, 195-205; en preparación, un trabajo de conjunto sobre el tema.

${ }_{18}$ Vide ex. gr. la inscripción CIL II 3271, con un flamen Augustalis in Baetica, de época de Domiciano (sobre el significado del primus que sigue en el epígrafe, vide DEININGER, J., "Zur Begründung des Provinzialkultes in der Baetica", MDAl(M) 5,1964,169-173; PFLAUM, H.-G., "La part prise par les chevaliers romains originaires d'Espagne à l'administration impériale", en Les empereurs romains d'Espagne, Paris, 1965, 91 ss. [= IDEM, Scripta Varia II. La Gaule et l'Empire romain, París 1981, $338 \mathrm{ss}$.]; y, finalmente, FISHwICK, D. The Imperial Cult in the Latin West. Studies in the Ruler Cult of the Provinces of the Roman Empire [EPRO 108] I, Leiden - Nueva York - Copenhague - Colonia 1987, 224-229), así como CIL II 3270 (sobre cuya controvertida datación, en el s. Il o bien en el III, vide bibliografía en Humphrey, J.H., Roman Circuses, Los Angeles-Berkeley 1986, 360, n. 27), en la que se hace referencia al afirmado de una calzada desde Castulo hasta (la bética) Sisapo, a través del Castulonensis saltus, realizado por un procurador imperial de la Bética. Cf. también CIL II 3278.

19 Sobre otras partes del Imperio nos faltan las correspondientes investigaciones, pero nuestra impresión es que la cronología es similar; es posible desde luego que el punto final no coincida en todas esas regiones, y que deba situarse, en parte, algo más tarde que en Hispania.

$20 \quad$ Vide ahora STYLow 1995, 219-238; sobre las medidas del locus, p. 223.

21 Vide ex. gr., en Martos (Jaén), CIL II 1690 (D. M. s., I. p. XII, una estela con medidas intercaladas en un lugar inadecuado) y 1694 (D. M. S., I. p. XIIII <in fronte et in agro p.?> XII, un altar, o estela, con medidas incompletas); o bien la estela del Cerro de la Almanzora (Luque, Córdoba) de referencia en Recio Veganzones, A., "Nueva epigrafía tuccitana», Bol. Inst. Est. Gienn. $15 n^{\circ}$ 59, 1969, 39-42, n 56 (l. q. q. v. p. [---], Diis Man[ibus sacrum?]). 
poránea de los altares funerarios ${ }^{22}$. Tales piezas deben de proceder más - menos de época trajánea, y posiblemente no sea ninguna casualidad el que se aprecien en dos de ellas ciertas irregularidades en la forma de dar las medidas: en un caso han sido acomodadas donde no era debido y en otro están incompletas (vide n. 21). Nuestra estela, que, por razones paleográficas y demás, es alrededor de medio siglo más reciente, ya no se sitúa en esa línea de evolución; sus formulaciones, aparatosas hasta el límite del equívoco, responden menos a una falta de familiaridad con las viejas fórmulas que a ese nuevo estilo rimbombante, ya observado en el manierismo de la ordinatio y de nuevo presente en la última parte de la inscripción.

Con cincuenta pies en ambas dimensiones, es decir, 2500 pies cuadrados (unos $225 \mathrm{~m}^{2}$ ), se sitúa nuestro locus sepulturae en el grupo puntero de los loca hispanos con medidas conocidas, los cuales tienen, en su gran mayoría, una extensión de 8-20 pies in fronte y 10-20 pies in agro ${ }^{23}$; algo muy similar, pues, a lo que ocurre en Roma, sólo que en este caso, debido a la escasez de suelo disponible, las medidas por debajo de 10 pies son mucho más frecuentes ${ }^{24}$ que en Hispania ${ }^{25}$. Por otro lado, las medidas únicas - ya sea in fronte o in agro- situadas entre los 20 y los 50 pies, que p.e. en Aquileia aparecen en más de la mitad de los casos ${ }^{26}$,

22 Sobre esa evolución, vide STYLow 1995, 225-226. Probablemente sea correcto ver la pedatura y la consagración a los Manes como dos aspectos del empeño por asegurar la inviolabilidad de la tumba: en un caso, a través de la determinación exacta del locus, y en el otro, de manera todavía más fuerte, por su incardinación en la esfera sacral.

${ }^{23}$ La correspondiente relación, en RodrigUez NEILA, J.F., "Aportaciones epigráficas I", Habis $14,1983,84-185$, quien vuelve sobre el tema en su articulo "Espacios de uso funerario con indicación de medidas en las necrópolis romanas", Conimbriga 30, 1991, 61-95.

${ }_{24}$ De acuerdo con la relación de ECK, W. ("Römische Grabinschriften. Aussageabsicht und Aussagefähigkeit im funerären Bereich”, en Römische Gräberstraßen. Selbstdarstellung - Status Standard, von HesBerg, H. - ZANKER, P. edd., ABAW 96, Munich 1987, 63 n. 12), los loca de más de doscientos pies cuadrados constituyen poco más del tercio de la totalidad; las medidas hasta un máximo de diez pies representan el $28 \%$ de los casos, pero, hasta un máximo de doce, bastante más de la mitad (ibid. p. 82).

25 La medida de un pie correspondiente a la lectura de HÜBNER en CIL II 5067 (Igabrum) y considerada como minimo absoluto por RodRiguez NeILA (o.c. $185 \mathrm{n} .148$ ) no debe ser tomada en consideración, puesto que en dicho epígrafe hay que leer, en cualquier caso, $p$ (edes) $L$ - lo que significa que, con $18 \times 50$ pies, era ya un locus de dimensiones considerables, situado de hecho en la zona de los loca que consideramos grandes.

${ }^{26}$ La relación, en CALDERINI, A., Aquileia romana, Ricerche di storia e di epigrafia, Milán 1930, 431-442; como era de esperar, no hay cambios al respecto en el material aquileyense mejorado por Brusin, J.B. (Inscriptiones Aquileiae, Udine 1991/93, donde véanse pp. 1351-1354). Según la relación de EcK (l.c. 83), las medidas de $20-50$ pies in fronte constituyen casi la mitad de los casos en CIL V (regiones $\mid \mathrm{X}-\mathrm{XI}$ ), pero sólo aproximadamente una cuarta parte en CIL XI (regiones VI.VIII). 
aquí ni siquiera representan un $20 \%$. Los loca grandes de verdad, con medidas de 100 pies y más, en una o en ambas dimensiones, son por todas partes extraordinariamente raros ${ }^{27}$, pero resulta llamativo el hecho de que en Hispania - dejando aparte un caso de Carthago Nova- ${ }^{28}$, se concentren en el conventus Astigitanus, y aquí, a su vez, al pie del sistema Subbético, en el sur de las provincias de Córdoba y Jaén; de esta zona, concretamente de una villa rustica situada en las proximidades de Castro del Río, proceden las medidas más grandes conocidas hasta ahora: $225 \mathrm{x}$ 150 pies ${ }^{29}$. Las siguientes son todas medidas únicas ${ }^{30}$ : 130 pies en una estela de la necrópolis de Alcaudete ${ }^{31}, 120$ pies en una del Monte Horquera, entre Baena y Nueva Carteya ${ }^{32}$; luego, siguen ya una estela terminal de las proximidades de Martos con 85 pies ${ }^{33}$, una estela de una villa rustica situada entre Cabra y Monturque con 55 pies $^{34}$ y la nuestra. Resulta evidente, como era de esperar, que los loca de grandes dimensiones se establecian de forma preferente, aunque de ningún modo exclusiva, en zonas rurales; pero también que, tanto las dimensiones absolutas como las medias, dependían en gran medida de circunstancias y tradiciones locales. Por regla general, en Hispania, los datos de las medidas se encuentran en estelas, no en tábulas fijadas en un mausoleo, o en sillares encastrados en la pared del mismo ${ }^{35}$. Hasta ahora no conocemos ningún caso en que las medidas se refieran con seguridad al área cubierta por un mausoleo.

27 Roma: CIL VI 11786, 13876, 23090, 24926, 26259, 30074, 30075 y 30076 (este último, con $500 \times 500$ pies, es uno de los loca más grandes que tenemos atestiguados; cf. también los cuatro iugera de ILS 4998); Aquileia: ocho ejemplos en Bqusin, la medida mayor: ped. CXX[-- $]$ ( $\left.n^{\circ} 628\right)$. En la tabla de EcK (o.c. 83), aparecen medidas in fronte de cien pies y más en siete de los quinientos seis casos de CIL V, y en seis de los doscientos setenta y ocho de CIL XI.

${ }^{28}$ CIL II 3444 (120 x 90[?] pies).

29 Ambas medidas se encuentran en parte in rasura sobre cifras probablemente más pequeñas; vide Rodriguez NeILA (o.c. 178-192 $n^{\circ} \mathrm{V}=\mathrm{AE}$ 1984, 536), con un comentario muy amplio. La estela, de sección de cuarto de cilindro, muestra en la cara curva unas concavidades para introducir las estacas de la cerca del locus.

30 En Hispania no se explicita nunca el producto de la medida in fronte e in agro, es decir, la superficie en pies cuadrados; de modo que, cuando aparece una sola medida - lo que no es raro, las más de las veces en la forma "l/ocus) $\rho$ (edum) tot»-, cabe bien pensar que se nos está dando el lado de un locus cuadrado, y no sólo la extensión in fronte, que nos dejaria sin conocer la superficie, y mucho menos el número de pies cuadrados, que no serviría para su exacta determinación. En este sentido también M. RAoss, Diz. Epigr. IV, 1965, 1511 s.v. locus.

31 CILA Jaén 645.

32 CIL II 1598; no está claro si la inscripción salió a la luz en una necrópolis suburbana, o bien en el campo, en las proximidades de una villa.

${ }^{33}$ Encontrada a $4 \mathrm{~km}$ de Tucci (CABEZÓN, A., "Epigrafía tuccitana", AEA 37, 1964, 121 n 19 = CILA Jaén 500, con una interpretación errónea).

34 AE 1983, 540.

35 Como ejemplo de una placa (además, marmórea) con las medidas de un locus, vide CIL $\|$ 1503 (Astigi). Sobre una posible ara con medidas, vide supra n. 21. 
La tercera y última parte del epígrafe contiene la conminación de una pena pecuniaria para el caso de violatio del locus (sepulturae), primera documentación en Hispania de tal instrumento jurídico, y - junto con una inscripción de Britannia ${ }^{36}$, Germania Superior ${ }^{37}$ y Numidia ${ }^{38}$, respectivamente-, uno de sus escasísimos testimonios en el Occidente del Imperio; en tanto que de Italia, sobre todo de Roma, y de las provincias balcánicas se conocen centenares de inscripciones de ese tipo, y el número de epígrafes griegos con penas sepulcrales, básicamente de Asia Menor, es todavía muchísimo mayor ${ }^{39}$. A pesar de la amplia bibliografía existente sobre el tema ${ }^{40}$, hay aspectos esenciales de ese instrumento - según opinión general, ignorado por los jurisconsultos romanos y sólo conocido para nosotros a través de las fuentes epigráficas- todavía controvertidos, por no decir totalmente oscuros. Por ello, intentaremos precisar algunos de esos aspectos, a partir del análisis de la forma peculiar de prescribir la pena que tenemos en nuestra inscripción.

La formulación conminatoria aparece aquí de un modo muy curioso y totalmente singular para el género. La construcción de gerundivo violandum putaverit, que se encuentra en la premisa en lugar del futuro perfecto violaverit que era de esperar, podría incluso producir la impresión, en un lector ingenuo, de que aquí se aceptaba, con una especie de ironía, el punto de vista del malhechor, quien, a su vez, justificaría su acción con el argumento de la necesidad ("si alguien cree que debería violar»); ése es desde luego el significado original de la combinación de un verbum sentiendi con una construcción de gerundivo como objeto. Si, además, el sujeto de la frase es la única fuente de perpetración de lo considerado como necesario o conveniente, entonces esa construcción podría llegar a ser la

${ }^{36}$ CIL VII 292 = RIB 754 (cerca de Kendal, en Lake District; según BIRLEY, E., en RIB, de comienzos del s. III.)

${ }^{37}$ El famoso "testamento del Galo" (CIL XIII 5708 = ILS 8379), que sólo conocemos por tradición manuscrita, y sin datos de hallazgo, pero que, en razón de la mención de la civitas Lingonum como comunidad beneficiaria, debe de proceder de la zona de Langres. Tradicionalmente se fecha en época de Trajano (vide Dessau, n. 29 ad ILS 8379).

38 CIL VIII 19174.

39 La relación más completa (incluyendo numerosas inscripciones griegas), aunque ordenada temática, no geográficamente, la sigue ofreciendo GıoRGi (p. $26 \mathrm{ss}$.). Selecciones de ejemplos tenemos en ILS 2796 ss. y 8216 ss., en FIRA III 257 ss. y en Rossi passim; testimonios cristianos numerosos de los siglos IV y V, en DIEHL, ILCV 395 ss. y 810 ss.

40 Bibliografía, en KLINGENBERG, G. (Reallexikon für Antike und Christentum XII, Stuttgart 1983, 635 ss., con un breve status quaestionis, ibid. col. 622 ss.). 
expresión de la voluntad de consumar el hecho, y, ulteriormente, la transcripción del hecho consumado mismo, en la medida en que se presenta realizado de forma premeditada ${ }^{4 i}$. Debido a su altisonancia, tan característica de las claúsulas retóricas, se prestaba esa construcción para un lenguaje ampuloso, por lo que fue gustosa y casi estereotipadamente utilizada en la jerga cancilleresca de las constituciones imperiales de la Antigüedad tardía ${ }^{42}$, unas veces en la primera persona del pluralis maiestatis, para la transcripción de las disposiciones de gobierno del emperador ${ }^{43} y$ otras, como aquí, en tercera persona, para la designación de un hecho punible, principalmente en una frase condicional ${ }^{44}$. En el segundo caso sobre todo, se ve bien hasta qué punto se ha alejado el significado del sentido original. Con el uso frecuente, la frase se había desgastado tanto que ya no se percibian sus distintos elementos. Se habia convertido en la expresión perifrástica de un acto realizado con conocimiento y voluntad, ya fuera premeditado o no: violandum putavi $=$ volens, non invitus violavi ${ }^{45}$.

El hecho de que, en nuestro epígrafe, se utilice esa circumlocución de la misma manera que en las constituciones imperiales resulta, con todo, menos sorprendente que el que aquí aparezca más de un siglo antes que en las constituciones conocidas ${ }^{46}$; lo que, por una parte, muestra que el

4. Si, ex. gr., dice Cicerón, en calidad de procónsul: de duobus generibus edicendum putavi (Att. 6, 1, 15), lo que quiere decir con ello es: edixi, quia necessarium (consentaneum) putavi. HEY, O. ("Aus dem kaiserlichen Kanzjeistil», ALG 15, 1908, 55-62) ha analizado la evolución de significado de esa construcción, por lo que remitimos igualmente a su estudio en relación con lo que sigue.

${ }_{42}$ MACMullen, R. ("Roman Bureaucratese", en IDEM, Changes in the Roman Empire. Essays in the Ordinary. Princeton 1990,71) se refiere al lenguaje burocrático de la Antigüedad tardia como sigue: "Its dominant feature is obscurity. That it prefers two words where one will do ...". Sobre el gusto por las cláusulas, vide SALOmiES, O., "Observations on the Development of the Style of Latin Honorific Inscriptions during the Empire", Arctos 28, 1994, 103 ss.

43 Ejemplos de las constituciones imperiales, a partir del 287 d. C., en HEY o.c. 57.

44 De los ejemplos reunidos por HEY (o.c. 58) mencionamos aquí solamente dos; el más antiguo está tomado del edictum de pretiis de Diocleciano (praef. 19): ab eiusmodi ... noxa immunis nec ille praestavitur, qui ... species ... necessarias ... exist<u>maverit subtrahendas; el otro es del año 407 d. C. (Cod. Theod. 8, 5, 66, 2): quod si quis ducum ... temerario animo ea quae decernimus contemnenda putaverit, ... auri inlatione multabitur (también sintácticamente, un auténtico paralelo de nuestra inscripción).

${ }_{45}$ Ut nullus putet se violare, es decir, con infinitivo, en CIL V 8734. Igual de verboso es el uso, muy frecuente en las conminaciones de pena (y probablemente también emanado de la lengua de los jurisconsultos), de voluerit, temptaverit y otros verbos semánticamente emparentados. El haber actuado con conocimiento y voluntad era condición previa para la circunstancia juridicamente relevante del dolus malus (vide LAZZARINI 1984, 235 n. 58, con bibliografía).

46 Dificilmente podria haber entrado en uso esa circumlocución antes del s. II, puesto que en las leyes, edictos y textos juridicos similares más antiguos se emplea, sin excepción, hasta la época de Trajano la forma simple. 
lenguaje técnico de los juristas le había encontrado pronto el gusto a las circumlocuciones rimbombantes de ese tipo, y, por otra, la rapidez con la que eran asumidos, en zonas aparentemente relegadas, no sólo los nuevos instrumentos creados por el derecho, sino incluso también las extravagantes florituras del lenguaje jurídico.

Las conminaciones de pena eran desconocidas hasta ahora, según se ha dicho, en las inscripciones funerarias hispanas, donde, aparte de disposiciones como hoc monumentum heredem non sequetur, son rarísimas las estipulaciones de un fundador de tumba, y donde incluso las maldiciones, tan frecuentes en otros lugares, sólo están atestiguadas una vez — para el caso de la violatio del numen de un muerto- ${ }^{47}$. ¿Qué significa, pues, en concreto en nuestra inscripción locum (sepulturae) violare? A primera vista podría parecer como si se tratara de una prohibición de ultrajar la tumba de alcance general (si quis). Sin embargo, las faltas graves, como el pillaje de la tumba y la profanación del cadáver, estaban sancionadas por el derecho penal imperial y castigadas con penas capitales ${ }^{48}$, mientras que para las lesiones del ius sepulchri, esto es, esencialmente del ius mortuum inferendi, se disponía de la actio sepulchri violati pretoria ${ }^{49}$. Ahora bien, ¿se hace referencia con ese locum violare a los supuestos de hecho comprendidos en la actio s.v.?

Lo primero que habría que aclarar al respecto es el significado del término violare. Considerado en sí mismo, es un término muy poco preciso y, además, se encuentra muy raramente en las conminaciones de pena sepulcral de las inscripciones: en época clásica, sólo en Roma y su entorno ${ }^{50}$; en la Antigüedad tardía, también en inscripciones cristianas del Adriático septentrional ${ }^{51}$, casi siempre en combinación con otras prohibiciones del mismo tipo, tal como las conocemos, en variadísimas formulaciones y

${ }^{47} \mathrm{CIL} \mathrm{II/77,} 44$ (Iliturgi, primera mitad del s. I d. C.): [si quis] numen eius viola/verit luppiter Optimus M]aximus Dique Pena[tes eum omnibus bonis om]nique fortuna fa[ciant expertem]. En inscripciones paleocristianas hay, por el contrario, más ejemplos: asi, CIL $\mathbb{I}^{2} / 7,678$ (Córdoba), o también CILA Jaén 587 (Carchel, Jaén), donde, en cualquier caso, es mejor leer: si quis sepulcrum inquietaverit, istum cum ludam traditorem abeat at ignum (scil. ad ignem).

48 De VISSCHER 150 sS.; KASER, M., Das römische Privatrecht $I^{2}$, Munich 1971, 380, nn. 42 y 43; cf. KLINGENBERG, RAC XII, $621 \mathrm{~s}$.

49 Vide KASER 69 SS.

50 CIL VI 24799: quisquis hoc mon. violaverit aut titulum deasciaverit (vide $\mathrm{n} .78$ ) aliove quo nomine inscripserit, ...; 29913: si quis titulum meum violaverit, ...; 29934: hoc sepulcrum sive mon. si quis violaverit, ...; XIV 1153: quisquis hunc titulum sive mon. sive sepulcrum est deacsiaverit aut violaverit, vendiderit, ...; Not. Scavi 1888, 725: qui hoc violaverit ... y AE 1974, 332: si quis voll]ueri[t] violare loculm nostr]um ...

53 EX. gr. CIL III 2631 (ct. 2632) y $\vee 8734$. 
combinaciones, por otras disposiciones sobre tumbas, con o sin conminación de pena. A pesar de toda la diversidad de formulaciones y del énfasis otorgado a uno $u$ otro aspectos ${ }^{52}$, la aparente homogeneidad de los testimonios -el fundador de la tumba quiere asegurar, con la conminación de pena, la eficacia de sus prohibiciones de enajenación u otra disposición de la tumba, de deposición de personas para las que no está destinada, de causar daños materiales al enterramiento y de cambiar el texto de la inscripción- permite concluir que se trata siempre de la misma institución jurídica ${ }^{53} \mathrm{y}$, por lo tanto, que con el simple violare de nuestra inscripción se presupone el mismo paquete de prohibiciones ${ }^{54}$.

En conjunto, las penas sepulcrales producen la impresión de que los supuestos indicados en ellas son idénticos en lo esencial a los comprendidos por la actio s.v. En tal caso, habría que preguntarse, por un lado, por el fundamento jurídico en virtud del cual podía un particular prohibir actos y establecer penas para los infractores de tales prohibiciones a su entera discreción, siendo así que esos mismos actos estaban ya sancionados por el derecho vigente; por otro, por el sentido de semejante duplicidad. ¿Se complementaban ambos procedimientos, o bien se hacían la competencia ${ }^{55}$ ?

Para esa aporía señaló ya Giorgi una salida, aceptada, sin embargo, tan sólo por unos pocos ${ }^{56}$. El resultado de su minucioso análisis de las fuentes epigráficas es que los actos prohibidos y castigados con penas en las inscripciones - junto a las enajenaciones, ante todo la deposición de extraños - no se diferencian, en principio, de los supuestos que se considera que entran bajo el concepto edictal de la actio s.v. Sin embargo, mientras este procedimiento otorgaba al heredero, o a otras personas con capacidad de disponer, una protección procesal contra la violación de su ius sepulchri por parte de terceros, es decir que (con la acción particular) castigaba las violaciones de los derechos de los herederos, y en cierto

52 En GıORGı 26 ss., una lista ordenada tipológicamente; las formas locales se encuentran relacionadas en Rossi 127 ss.

${ }_{53}$ También KASER (39 n. 107) asume que, incluso cuando sólo aparecen cláusulas prohibitorias sueltas, a menudo en forma sumaria e imprecisa, hay que interpretarlas como si se mencionaran todas.

54 Véase Giongı 45-46.

55 Asumen la competencia, sobre todo, DE VISSCHER (116 s.) y KASER (83 n. 298).

56 Ex. gr. AlbeRTARIO, E., Studi di diritto romano II, Milán 1941, 65; y, recientemente, también LAZZARINI (1984, 217 Ss.; IDEM 1991, passim). DE VISSCHER 115 ss. adopta el planteamiento de GIORGI, pero ve como objetivo de las penas sepulcrales en general la protección de los sepulcros familiares. KASER ( 83 n. 298) interpreta como errónea la tesis de GıORGI ("Sepulkralbußen auf die leichteren, nicht gerichtlich strafbaren Handlungen beschränkt"). 
modo también (con la acción popular) garantizaba la tranquilidad de la tumba ${ }^{57}$, se referian, en cambio, las prohibiciones sancionadas con penas sepulcrales ( $y$, en definitiva, todas las prohibiciones epigráficas de usar del derecho de sepultura) a actos que habrían sido lícitos si el fundador de la tumba no los hubiera prohibido al heredero y a cualesquiera otros sujetos con capacidad de disponer - porque estos últimos, y no terceras personas, son los aludidos con la fórmula si quis de las penas ${ }^{58}$.

Puesto que, al lado de la prohibición - absoluta o especificada - de ulteriores deposiciones, la prohibición de enajenar constituye la parte principal del conjunto de los actos sancionados con penas, cabe preguntarse, naturalmente, en qué medida una tumba, que es un locus religiosus, y por ello una res extra commercium, podría, en definitiva, haber sido vendida.

57 Dig. 47, 12, 3 pr: Praetor ait: cuius dolo malo sepulchrum violatum esse dicetur, in eum in factum iudicium dabo, ut ei, ad quem pertineat, quanti ob eam rem aequum videbitur, condemnetur. si nemo erit, ad quem pertineat, sive agere nolet: quicumque agere volet, ei centum [aureorum] $<$ milium sestertium > actionem dabo. si plures agere volent, cuius iustissima causa esse videbitur, ei agendi potestatem faciam. si quis in sepulchro dolo malo habitaverit aedificiumve aliud, quamque sepulchri causa factum sit, habuerit: in eum, si quis eo nomine agere volet, ducentorum [aureorum] <milium sestertium > iudicium dabo. El heredero, que, según el derecho clásico, adquiria por herencia la tumba junto con las propiedades del difunto, se convertia por ello - tanto si era heredero único como si coheredaba- en el propietario de la misma (KASER 39). Sin embargo, puesto que se mantenian igualmente los derechos de aquellos que, en virtud de la tradicional normativa sobre los sepulcros emanada del derecho sacral, poseían un derecho de enterramiento, a saber, los descendientes familiares, se veia obligado el heredero a permitir la deposición de todos esos miembros de la familia, del mismo modo que se encontraban también legitimados todos los sucesivos herederos del fundador, con independencia de la cuantía de la parte (Dig. 11, 7, 6). Por otro lado, el fundador podia, por testamento o bien por medio del epígrafe funerario, tanto autorizar como prohibir ulteriores deposiciones, y, en definitiva, determinar a voluntad el círculo de derechohabientes en relación con la utilización de la tumba (sobre el fundamento jurídico de esa capacidad, vide infra). Habia, por consiguiente, en la práctica, sepulcros familiares, sepulcros individuales y sepulcros hereditarios (sobre las correspondientes definiciones de los jurisconsultos, vide KASER $37 \mathrm{ss}$.). Is ad quem pertineat del pasaje citado del Edicto es, pues, el heres del sepulchrum, quien no sería, sin embargo, derechohabiente de deposición, en el caso de que el fundador se lo hubiera reservado para sí mismo, o en el caso de que lo hubiera hecho para si mismo y para algunos o todos sus descendientes familiares, y el heres en cuestión no fuera uno de ellos. Frente a eso, la diferenciación de DE VISSCHER entre dos tipos de sepulcros mutuamente excluyentes - de un lado, el sepulcro hereditario, al que se refiriría la actio s.v., y, de otro, el sepulcro familiar, que estaría protegido por las penas sepulcrales, resulta artificial, tal como lo reconoce el propio autor (p. 117), y no está justificada por lo que se lee en los epígrafes.

58 Ello resulta, con toda claridad, de numerosas inscripciones: ex. gr. CIL VI 29976: si heres meus ... contra voluntatem meam ...; XIII 5708 (= LLS 8379) linea 33 s.: haec poena omnibus dominis huius possessionis in perpetuu[m] imponatur (ibid., línea $30 \mathrm{ss.,} \mathrm{donde} \mathrm{el} \mathrm{aludido,} \mathrm{es} \mathrm{decir} \mathrm{el}$ heredero, es invocado incluso por su nombre); VI 14027: quisque mi heres erit; 9485: quis ultimus ex nomine nostrorum posterorumque eorum y $X 3750$ : quis ex his qui suprascripti sunt (de modo similar, VI 10238a, 10876, 14190, 26913, 29289 y 29908); con prohibición dirigida expresamente al heres o a los heredes: III 2226; VI 3554, 8431 y13387; IX 4822; X 3071; XII 5219; XIV 166 y 1236. 
El intento de restringir la prohibición al tiempo comprendido entre la construcción de la tumba y la primera deposición, que convertiría en religiosus el locus purus, debe ser desechado, puesto que una tal prohibición habría sido totalmente superflua ${ }^{59}$, aparte de que en numerosas inscripciones se introduce la prohibición con la mención post obitum. Según la opinión dominante, con la introducción ritual del primer cadáver o de las primeras cenizas se convertía en religiosus de hecho la totalidad del locus, incluidos los lugares de deposición no ocupados; sobre estos últimos tenían, sin embargo, los derechohabientes un derecho de deposición, el ius sepulchrum individual, que era en la práctica enajenable, si no se oponía a ello la prohibición del fundador de la tumba ${ }^{60}$. La prohibición de enajenar es, pues, tan sólo un aspecto parcial de la prohibición de enterrar a extraños, en virtud de la cual quedaba también prohibida la transferencia mediante pago de los puestos libres de la tumba. En nuestro contexto, hay que tener en cuenta que todos los que tenian un ius sepulchri sobre una determinada tumba, es decir los que, según las estipulaciones de la inscripción funeraria - por pertenencia a la familia, por designación especial en la inscripción o como herederos- quedaban legitimados para una futura deposición en esa tumba, lo estaban también (de acuerdo con Dig. $47,12,3$ pr.) para ejercer la actio s.v., pero que la capacidad de disponer de esas plazas, lo mismo que el círculo de los derechohabientes, podía resultar limitado por prohibiciones - recrudecidas en parte por penas pecuniarias- del fundador de la tumba, a las que quedaban igualmente ligados otros futuros herederos y otros posibles derechohabientes.

La cuestión del fundamento jurídico de esas prohibiciones $y$, sobre todo, de las conminaciones de pena ha sido resuelta de modos muy diferentes por los investigadores, quienes han asumido, casi sin excepción, que aquéllas no iban dirigidas a los herederos sino a la generalidad ${ }^{61}$. La investigación antigua partía, o bien del derecho del testador a disponer de sus bienes testamentariamente sin limitación alguna, hasta el extremo de establecer también penas pecuniarias para los extraños ${ }^{62}$, o bien de una lex publica o fuente jurídica similar ${ }^{63}$, de la que no tenemos, sin embargo,

59 Véase KASER 30 ss., quien (p. 60 s.) acertadamente observa que, en vida del fundador de la tumba, éste habria podido protegerla por si mismo contra los abusos, y que, por otro lado, entre su muerte y la subsiguiente deposición no habria dado tiempo a enajenarla.

60 Vide KaSER 61-82.

61 Status quaestionis, en GIORGI 17 ss.; SCIALOJA, V., Teoria della propietà nel diritto romano I, Roma 1928, 183 ss.; KASEA 85 ss. y KLINGENBERG, RAC XIi, 628.

62 Así Huschke, PH. (Die Multa und das Sacramentum, Leipzig 1874, 315 ss.); en contra, DE VISSCHER (pp. 113 y 120) y KASER (p. 86).

63 Asi, sobre todo, MOMMSEN (Strafrecht 812 ss.); en contra, KASER (ibid.). 
huella epigráfica alguna ${ }^{64}$. Tampoco contienen nuestras inscripciones indicios de conceptos del derecho sacral, que, en opinión de algunos, estarían en el origen de las penas sepulcrales griegas - probablemente originarias del Asia Menor suroccidental - ${ }^{65}$, a cuyo modelo se remontan las penas sepulcrales romanas con bastante probabilidad ${ }^{66}$. A pesar de ello, no hay que pensar que los romanos hayan injertado, con más pena que gloria, en su propio derecho "una institución que les era extraña" ${ }^{67}$, puesto que las disposiciones funerarias - mandamientos y prohibiciones, junto con conminaciones de pena y promesas de premios para delatores ${ }^{68}$ - se pueden remitir sin dificultad al derecho de cada cual, cimentado en la Ley de las Doce Tablas, a legem dicere suae rei, esto es, a configurar su ámbito jurídico personal y su esfera sacral privada a su total albedrío, mientras no contravenga las leyes vigentes ${ }^{69}$. Sus fundamentos jurídicos serian, pues, los mismos de las disposiciones testamentarias y de las fundaciones privadas, con las que presentan también otros rasgos comunes, incluidas las conminaciones de pena ${ }^{70}$.

Mientras sobre la eficacia de las conminaciones de penas sepulcrales apenas existe hoy ya duda ${ }^{71}$, reina una considerable confusión en la cuestión de cómo se producía el pago de la pena a las corporaciones beneficiarias. Como tales, aparecen, en Roma y su entorno inmediato, los collegia de los Pontífices y de las Vestales, y, en el resto de Italia y en las provincias, una caja municipal, o bien el aerarium populi Romani, en cuyo

64 La lex mencionada en diversas inscripciones (ex. gr. CIL VI 7458, 10246 y 26445 [vide KASER 24 n. 34]; XIII 5708) no es otra cosa que la ordenación del propio fundador de la tumba (cf. también CIL VI 13785: avdersus (!) hanc scriptura(m); 22518: contra hanc inscriptionem).

65 Así, sobre todo, LATTE, K. (Heiliges Recht, Tubinga 1920, 88-96), quien hace proceder las penas sepulcrales de una originaria "pena sacral».

${ }_{66}$ Tesis impugnada por Behrends, O. (en: Jankuhn, H. - Nehlsen, H. - Roth, H., Zum Grabfrevel in vor- und frühgeschichtlicher Zeit, Abh. Akad. Göttingen, phil.-hist. KI. 113, 1978, 92). Está claro que las penas sepulcrales griegas se remontan al comienzo de la época helenística, pero aquí no se trata simplemente de un ante hoc propter hoc: siendo los paralelos lingüísticos y materiales tan estrechos, no se puede pensar en un desarrollo independiente en Roma.

${ }_{67}$ Asi LATTE I.C. 90.

68 Ejemplos en MOMMSEN, Strafrecht 820 n. 2 y KASER 89.

69 Ese pensamiento ya en DE VISSCHER 86. 121; DüLL, R., «Studien zum römischen Sepulkralrecht II", Atti Congr. Intern. Verona III, 1951, 168 ("edicto unilateral del autónomo fundador de la tumba"); y, más desarrollado, en KASER 24. 87.

70 Sobre esos paralelos ha llamado la atención WÖRRLE, M., Stadt und Fest im kaiserzeitlichen Kleinasien, Munich 1988, $170 \mathrm{~s}$.

${ }_{1}$ Una pura función disuasoria, "ohne rechtliche Verbindlichkeit", les atribuyó, en su dia, Ziebarth, E. (Hermes 30, 1895, 57-70), mientras SCHERILlo, G., (Lezioni di diritto romano. Le cose. Concetto di cosa. Cose extra patrimonium. Milán 1945,64) las consideraba como una institución de la época de la introducción de la actio s. v., que habria mantenido en las inscripciones una existencia fósil, sin significación práctica. 
lugar encontramos muy pronto el Fisco; son frecuentes las acumulaciones de varios beneficiarios ${ }^{72}$. De la costumbre generalizada en Asia Menor de levantar un documento de carácter público, con las disposiciones sepulcrales y las correspondientes conminaciones de multa, que quedaba depositado en el archivo de una comunidad (por regla general la de los beneficiarios), o en el del gobernador ${ }^{73}$, no se encuentra ninguna huella en las inscripciones latinas. La publicación se producía por la simple colocación de la inscripción en la tumba, si bien un entendimiento previo con la corporación beneficiaria, en aras de la eficacia de la conminación, podría haber sido acostumbrado, 0 , incluso, de regla ${ }^{74}$. Por el contrario, sobre una obligación general de anunciar tales medidas públicamente, p.e., en Roma, en la sede de los Pontífices, y, fuera, en las comunidades beneficiarias, tal como lo asumieron Mommsen y Düll ${ }^{75}$, que hubiera sido necesaria para la validez de las mismas, no hay hasta ahora ningún indicio, como tampoco lo hay de la, igualmente postulada por Mommsen, jurisdicción de los Pontífices en lo concerniente a las penas sepulcrales que cayeran dentro de Roma - por encima de la supervisión general por parte de los sacerdotes de la res religiosa y del arbitraje de los litigios ${ }^{76}$.

Sin embargo, creemos que se pueden llegar a conocer detalles sobre el procedimiento de imposición de penas en favor de corporaciones municipales, es decir, el caso que aparece en nuestra inscripción de Alcaudete, así como sobre su fundamento jurídico. Sobre las modalidades del procedimiento, proporcionan información dos inscripciones latinas, ambas de

72 Ejemplos selectos, en RossI 128 ss. y KASER 83. Rara vez se destinan las penas a collegia. A partir del s. IV aparece también la Iglesia como destinataria. Los templos, que en el oriente griego eran designados con mucha frecuencia como beneficiarios, faltan por completo en las inscripciones latinas.

73 Ejemplos, en Rossi 151 ss. Sobre praxis y terminología, WÖrale, M., "Maßnahmen des Quintus Veranius zur Reform des Urkundenwesens", en Myra. Eine lykische Metropole in antiker und byzantinischer Zeit (BORCHHARDT, J. ed.), Berlín 1975, 269 ss.

74 De VISSCHER $121 \mathrm{~s}$.; KASER 68; KLINGENBERG, RAC XII, $623 \mathrm{~s}$. Puesto que las prohibiciones iban dirigidas a los herederos y demás possessores de la tumba, que eran quienes más posibilidad - e interés- podían tener de cambiar o hacer desaparecer el epigrafe de la misma, es de suponer que hubiera alguna forma de registro, de suerte que, en el caso de un ulterior proceso, no se dependiera tan sólo de la declaración de testigos. Un acuerdo sobre el destino de una pena pecuniaria, como la reparación de acueducto que se menciona en una inscripción tiria (REY-COQUAIS, J.-P., Inscriptions grecques et latines découvertes dans les fouilles de Tyr [1963-1974] 1. Paris $1977, n^{\circ} 108$ ), es singular incluso en el ámbito griego.

75 Strafrecht $816 \mathrm{~s}$.; DüLL O.c. 166-171.

16 Contra la idea de MOMMSEN (Strafrecht 819 y Staatsrecht II 71, basándose en CIL VI 10284 y 10791 - cf. también 10675 y 35987) de que el cobro de las penas se realizaba a través de los Pontifices, por via administrativa ("Administrativprozeß"), vide DE VISSCHER 143 ss. y KASER 87 s., cf. 26 ss.). 
Aquileia. Una de ellas se conoce de hecho desde hace casi un siglo, aunque ha permanecido en la sombra hasta hace poco, sin haber sido utilizada en este contexto ${ }^{77}$. Se encuentra en un altar funerario, y sólo se conserva su parte inferior:

[---] monimentum [--- or]-

natumq(ue) est. ne quis haec

aliave vendere exacisclare ${ }^{78}$

destruere corpus ossave alie-

5 na inferre velit. quod si quis ita

fecerit, tum, quanti ea res fuerit, quadruplam summam rei p(ublicae) Aquil(eiensium)

pendere debeto (?).

ipsius rei persequendae querella Aquil(eiensium)

esto

Mientras la lista de las prohibiciones no se sale del marco habitual de Aquileia y otros lugares ${ }^{79}$, la pena, singularmente, no se cifra en una cuantía fija, sino que se establece en el cuádruplo quanti ea res fuerit. Esto recuerda el procedimiento de la actio in bonum et aequum, donde tampoco se trata de indemnizar, sino que se establece la poena como expiación penal del agravio, partiendo frecuentemente el juez, en la correspondiente aestimatio, del valor del bien afectado, para fijar la pena en una cuantía igual, doble, triple o cuádruple del valor estimado ${ }^{80}$. Ahora bien,

77 La lectura de la primera publicación de MAIONICA, E. (Mitth. d. K. K. Centr. Comm. z. Erforsch. u. Erhalt. d. Kunst- u. hist. Denkmale N. S. 23, 1897, $72 \mathrm{n}^{\circ} 53$ ) ha sido confirmada, en to esencial, por PANCIERA, S. (Latomus 19, 1960, 703), mediante calco, y es la que asume - sin datos sobre la fuente- LAZZARINI (1991, 59, $n^{\circ}$ viii); sin embargo, vide Brusin, J.B., Inscriptiones Aquileiae, Udine 1991/93, 3554, con una lectura mejorada. - En las líneas 1-2 damos el texto de PANCIEAA; el de BRUSIN, mon[umentum orlinatumq. est [ne quis haec]. - En la linea 7 , frente al quaer(ere) ullam de MAIONICA (donde, para PANCIERA, se habria escrito erróneamente ullam por illam), el quadruplam de Brusin constituye una lectura a todas luces preferible. - Según BRuSin, la lectura de las líneas 8-9 no está libre de dudas. En la linea 8, MaIONICA daba [-.- poenae] nomine [--] esto; aunque, según PANCIERA, nomine y esto ya no se podrian leer. Poenae nomine dare debeto (o un imperativo similar) seria lo que daría mejor sentido. - En relación con la linea 9 , se oponen al ius rei $p$. Aquil. de MAIONICA y PANCIERA no sólo el uso paralelo de querella en CIL VI 10284 sino también el hecho de que el derecho a entablar el proceso fuera asignado a la ciudad de Aquileia, y no, como sería de esperar, a los ciudadanos, o, eventualmente, a un magistrado.

78 Sobre exacisclare, y términos similares con el significado de shacer irreconocible un monumento en sus partes esenciales", vide PANCIERA, o.c. 707 n. 4, y LAZZARINi, S., Aiv. arch. dell'antica prov. e dioc. di Como 160, 1978, 135 ss.

79 Cf. ex. gr. CIL V 979 y 1496; BRUSIN 2722 y 2830.

Bo KASER, M., Das römische Privatrecht $1^{2}$, Munich 1971, 498-502; cf. 148. 
¿tendríamos en esa acción popular de persecutio de la pena -abierta, según el epígrafe, a cualquier ciudadano de Aquileia - una actio s.v., que, en su modalidad de acción particular, era igualmente una actio in aequum concepta, pero, como acción popular, también conocía penas de cuantía fija, tal y como son normalmente las penas sepulcrales ${ }^{81}$ ?

Ya Mommsen, a partir de la segunda de las inscripciones aquileyenses mencionadas ${ }^{82}$, había fundamentado la tesis de que las penas sepulcrales en favor de cajas de comunidades eran llevadas ante los tribunales municipales por vía de "acción privada popular» (que con ello pensara en la actio s.v. sólo se puede deducir indirectamente de su exposición), con recompensa para el actor ${ }^{83}$. Por su parte, la moderna investigación no ha dejado de percatarse de la analogía de las estipulaciones que se encuentran en esa inscripción con la actio s.v., pero sólo para considerar por ello, casi unánimemente ${ }^{84}$, el texto como una excepción, excluyéndolo, por consiguiente, de la discusión sobre las penas sepulcrales ${ }^{85}$. La inscripción, que se encuentra en un sarcófago fragmentado por la izquierda, se cierra, tras la prohibición de la deposición de extraños, con las palabras: si quis commiserit / [---]ius rei persecutio cuilibet de populo datur. Mommsen suplió en el CIL, después de commiserit, a comienzos de la última línea, [ve] ---], de modo que presumía la mención de una infracción más. Ese suplemento, aceptado en general ${ }^{86}$, impide ver, sin embargo, la auténtica construcción de la fórmula de la multa. No sólo el hecho de que no concuerden el tempus y el modus de los dos verbos, ni correspondan al estilo habitual de las penas sepulcrales, habria debido dar que pensar, sino también la expresión de populo, que, sin más determinaciones, resulta oscura. Puesto que, por la izquierda, han desaparecido aproximadamente las dos quintas partes del texto original, habría que dar por perdidas en la última línea, delante del texto conservado (si, como hace suponer la cui-

${ }^{91}$ Vide Dig. 47, 12, 3 pr. (supra, n. 57); cf. PARICIO, J., Estudio sobre las actiones in aequum conceptae, Milán 1986, 64 ss.

${ }_{82}$ CIL V $8305=$ ILS 8212 = BRUSIN 626 con fotografía.

83 Strafrecht $819 \mathrm{~s}$; cf. Staatsrecht 1171 (con lo cual asumia que las penas debidas al aerarium $p$. R. y al fiscus eran cobradas de la misma manera. Para la forma del procedimiento como iudicium recuperatorium municipal y el pago de recompensa al querellante a través del tribunal, remitia a la Lex Mamil. Rosc. LV). Esa tesis ha encontrado poco eco (en tono de aprobación se menciona en KLINGENBERG, RAC XII, 624; en forma escéptica, en KASER 88: "wie die Bußzahlung erzwungen wurde, bleibt ... unerkennbar").

${ }^{84}$ Solamente LAZZARINI 1984, 236 y 1991, 33 ss. apoya en ella la tesis de que las penas sepulcrales eran impuestas por via de la actio $s$. $v$.; sobre este aspecto, vide infra.

85 DE VISSCHER 120: "très exceptionelle"; KASER 83 n. 306: "singulär".

${ }_{86}$ Únicamente FabBrinI, F. (en: Novissimo Digesto Italiano XV, Turín 1968, 560, n. 36, VII, u), ha asumido la mención de una pena en la parte perdida. 
dada ordinatio de la inscripción, estaba centrado), alrededor de venticinco letras, correspondientes sin duda a la determinación de la multa pagadera a la res publica Aquileiensium - probablemente, como es habitual, una cuantía fija- expresada por medio del imperativo o el futuro de un verbo, con lo que quedaría claro de qué populus se trataba. La reclamación de la pena ([e]ius, [cu]ius, o bien [hu]ius rei persecutio) estaría abierta a cada uno de los ciudadanos de la ciudad, por vía de la acción popular - lo que aquí solamente puede significar con una actio s.v. ${ }^{87}$, tal y como disponen las leyes municipales para la multae petitio persecutio ${ }^{88}$. Por 10 demás, esas multas municipales se asemejan a las penas sepulcrales también en el hecho de que no revierten, como las poenae de las acciones e interdictos populares pretorios normales, al correspondiente actor, sino más bien a la caja municipal ${ }^{89}$.

Una decisión segura sobre la cuestión de si la actio para la imposición de las penas sepulcrales discurría normalmente, como en el caso de las multas municipales, ante un magistrado municipal, o bien ante el pretor -esto es, ante el gobernador, tratándose de una comunidad provincial como Aiungi- es, en cualquier caso, imposible. Aunque las cuantías de las penas ${ }^{90}$ exceden con mucho, en algunos casos, los límites estableci-

87 Asi tambièn LAZZARINI 1984, 233 ss. y 1991, 33 ss.

Be Ex. gr., Lex Urs. 97: eius pecuniae colon(orum) eius colon(iae) cui volet petitio esto, análogamente 125, 128, 129, 130, 131 y 132; Lex Salp. 26: eius pecuniae deque ea pecunia municipum eius municipi cui volet cuique per hanc legem licebit actio petitio persecutio esto; análogamente Lex Malac. 58, 62 y 67. Cf. SpItzL, TH., Lex Muncipii Malacitani, Munich 1984, 65 ss.

89 En contra de Casavola, F. (Actio petitio persecutio, Nápoles 1965, 76-88), quien asume que esas penas remitian al actor privado, véanse los contundentes argumentos de SIMSHÄUSER, W. (Iuridici und Munizipalgerichtsbarkeit in Italien, Munich 1973, 165 ss.) y SPITzL (o.c. 64 SS.). D'ORS, A. (Epigrafía juridica de la España romana, Madrid 953, 161) habla aquí de "acciones populares procuratorias". Lo que no sabemos es si el actor obtenia siempre como recompensa una determinada parte de la cuantía de la pena, o bien sólo en el caso de que la inscripción lo mencionara expresamente (vide supra, n. 68).

9o La mayoría de ellas se sitúan entre los 20.000 y los 50.000 sestercios, siendo raros los importes bajos y los altos (10.000 y 100.000 sestercios, respectivamente; ejemplos, en Rossı 137 ss. y 143 ss.). Los IIS 20.000 de nuestra inscripción se encuentran, pues, en el nivel más bajo de la media. Sólo excepcionalmente se rebasaba la pena de IIS 100.000 (200.000 para la habitatio vel aedificatio) establecida para la acción popular de sepulchro violato (CIL VI 35283: IIS 250.000; VI 13387: IIS 350.000; rara vez _y no sabemos si también a consecuencia de una acción popular - veía el culpable confiscada, en calidad de pena, la totalidad de sus bienes: CIL IX 136 y X 3750). Estas penas superan, con creces, las cuantias de las inscripciones griegas (por regla general interiores a los 2.500 denarios), sin razón aparente. El intento por parte de Rossi (154 ss.) de poner en relación la cuantia de las penas con el tamaño del correspondiente locus, no resulta convincente. A partir del s. Ill, las cuantias se dan cada vez más en denarios, en lugar de en sestercios, y, a partir del s. IV, en moneda de oro y en metales preciosos; sobre esa evolución, véase ROUECHÉ, CH., ZPE 105, 1995, 44. 
dos para la jurisdicción municipal ${ }^{91}$, también se encuentra atestiguado un importe de hasta 100.000 sestercios —es decir, el límite más alto hasta ahora de las multas sepulcrales, fuera de Roma- ${ }^{92}$, para cuya imposición procesal se prevé expresamente, al menos en un caso, la jurisdicción municipal ${ }^{93}$. Pero, por otro lado, la condena a consecuencia de una actio s.V. parece haber acarreado la infamia ${ }^{94}$, y, desde luego, la competencia de los tribunales municipales para las causae famosae estaba, cuando menos, muy limitada ${ }^{95}$.

El hecho de que las penas sepulcrales destinadas a las cajas municipales ${ }^{96}$ hubieran sido equiparadas, en razón del instrumento elegido para su imposición, la actio s.v., a las penas que gravaban la sepulchri violatio por obra de terceros, es una señal de que las disposiciones que había establecido el fundador de la tumba a través de una lex suae rei dicta gozaban, por principio, de la misma protección que -como uno de los aspectos principales de la religio privata que era- disfrutaba la tumba, y las normas públicas en general.

Por otra parte, en los escritos de los jurisconsultos que se nos han conservado, se encuentra al menos una huella de esa protección legal: un rescripto de Caracala establece que también el heredero que practica una deposición en un sepulchrum hereditarium contra la voluntad de su fundador puede ser perseguido judicialmente por sepulchri violatio ${ }^{97}$. Esta dis-

91 En determinadas condiciones, la lex Rubria de Gallia Cisalpina (cap.22, BRUNs ${ }^{7} 16=$ FIRA $\left.I^{2} 19\right)$ otorga poderes ejecutivos personales a los magistrados municipales en la actio certae cre-

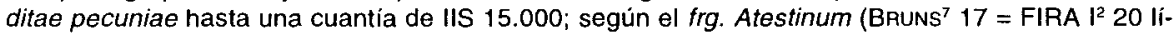
neas $4 \mathrm{ss}$ ), el magistrado municipal es competente para querellas infamantes, previa aceptación del demandado, si la cuantía de la pena no supera los IIS 10.000. La lex Irnitana (cap. 84) limita taxativamente la competencia de la jurisdicción municipal a los IIS 1.000 .

92 Lex Urs. 130 y lex Irnit. 96. D'ORs, A. y J. (Lex Irnitana, texto bilingüe, Santiago de Compostela 1988, 84 n. 100) consideran, sin suficiente fundamento, la última de esas dos multas en exceso elevada y, por ello, supuestamente no aplicable (véase también D'ORS, A., La Ley Flavia Municipal, texto y comentario, Roma 1986, 183). KASER, M.,(Das römische ZivilprozeBrecht, Munich 1966,128 ) admite una gran diversidad para las reglamentaciones locales.

93 Cf. SIMSHAUSER O.C. 162-164.

94 Dig. 47, 12, 1: sepulchri violati actio infamiam irrogat. Posiblemente se aluda en este singular pasaje al procedimiento penal contra la profanación de la tumba: véase KASER, M., ZRG 73, 1956,249 n. 131.

95 Véase KASER ibid. 248-249.

96 Que las penas pagaderas al aerarium p. R. y al fiscus fueran impuestas por vía de la actio s. $v$. (Como ya parece haber supuesto MOMMSEN) es algo que no se puede demostrar con las fuentes de que disponemos hoy por hoy, pero tampoco resulta inverosímil.

${ }^{97}$ Dig. 47, 12, 3: si quis in hereditarium sepulchrum inferat, quamvis heres, tamen potest sepulchri violati teneri, si forte contra voluntatem testatoris intulit: licet enim cavere testatori, ne quis eo inferatur, ut rescripto imperatoris Antonini cavetur: servari enim voluntatem eius oportere. ergo et si cavit, ut unus tantum heredum inferret, servabitur, ut solus inferat. 
posición, hasta ahora, que sepamos, puesta en relación con las penas sepulcrales solamente por Lazzarini ${ }^{98}$, llega al verdadero meolio de las disposiciones sepulcrales - tanto si estaban sancionadas con penas como si no. Con ellas pretendía el fundador dejar sentado, frente a los herederos, que quería compartir el lugar sagrado de su último descanso sólo con las personas designadas por él, y, en todo caso, con los descendientes de ellos -o bien no compartirlo con nadie, si, como quizá nuestra Fabia Albana, era el último miembro de su familia y no tenía descendientes.

Nuestra tesis de que, en caso de incumplimiento de esas disposiciones por parte de los herederos, el procedimiento para el cobro de las penas establecidas era la actio sepulchri violati se ve respaldada de manera esencial por el texto del mencionado rescripto. Es improbable, de suyo, que el emperador esté creando aquí derecho, por lo que debe de tratarse únicamente de la confirmación de antiguas disposiciones del ius honorarium. $Y$ precisamente las diferencias en el edicto entre distintos pretores, 0 en su caso gobernadores, podrían haber contribuido a la diversidad de las formulaciones que se encuentra en las disposiciones y en las penas, e, igualmente, explicar el hecho de que sean frecuentes las penas sepulcrales latinas en determinadas zonas del Imperio, mientras que en otras sólo aparecen de forma muy esporádica.

Sobre las razones para la adopción en Roma y en el occidente latino del instrumento jurídico griego de las penas sepulcrales, que, según el punto de vista general, habria tenido lugar en el tránsito del s. I al s. II, o incluso más temprano ${ }^{99}$, sólo se pueden hacer especulaciones. Es probable, como supone Kaser (84 s.), que uen una época anterior, el temor divino y las costumbres funerarias firmemente arraigadas hayan bastado

98 Mientras en 1984 (233 ss.) se mostraba todavía confundido por la dicotomia sepulcro hereditario/sepulcro familiar de los jurisconsultos, relacionando, en consecuencia, las penas sepulcrales exclusivamente con los sepuicros familiares, en 1991 (33 ss.) amplía ya el concepto de sepulchrum familiare, sobre la base de las fuentes epigráficas, de modo que pueda abarcar también a aquellos extranei a la familia a quienes el fundador de la tumba hubiera otorgado el ius sepeliri (en la práctica, también el ius mortuum inferendi). Queda por ver, desde luego, si ese concepto así ampliado sigue siendo una categoría jurídica operativa, pero el caso es que LAZZARINI Se aproxima con ello --al menos en el contenido- a nuestra posición, a saber, que las penas sepulcrales amenazaban sencillamente a todo heredero y a toda persona en principio legitimada para la disposición de la tumba, que actuara, sin embargo, en contra de la voluntad de su fundador, tal y como se manifestaba ésta en la inscripción.

${ }_{99}$ Un estudio sobre la extensión cronológica de las inscripciones latinas (y griegas) con penas sepulcrales es un desideratum. Los epigrafes latinos, con datación, más antiguos proceden de la época de Trajano y Adriano: vide DE VISSCHER (p. 115), quien, en todo caso, interpreta, en general, su aparición (cf. p. 119) como un intento (anacrónico, según su entender) de preservar la institución del sepulcro familiar, a la sazón amenazada de decadencia. 
para que todo el mundo, y especialmente los extranei heredes en relación con las tumbas familiares, se limitara a realizar las actuaciones debidas". Si fue una "progresiva secularización" lo que condujo a que las disposiciones del fundador de la tumba fueran seguidas de un modo más negligente, y hubo que darles eficacia con penas en algunos casos muy fuertes, eso no podemos saberlo. Sea como fuere, no hay que olvidar que, incluso en las partes del Imperio en las que son frecuentes las penas sepulcrales, se encuentran tan sólo en una pequeña parte de las inscripciones.

\section{V}

Para la localización de Aiungi es esencial saber si del hecho de que en nuestro epigrafe se mencione esa ciudad como perceptora del importe de la pena, se sigue necesariamente que el recinto funerario en cuestión perteneciera a su territorio. El caso es que la práctica totalidad de las inscripciones latinas con penas sepulcrales pagaderas a una caja municipal han sido encontradas en el territorio del municipio en cuestión ${ }^{100}$; sin embargo, ya Mommsen, a partir de la inscripción CIL X 5860 (= ILS 8234 ) de Auximum, en la que aparecen como perceptoras, además del Fisco, las cajas municipales de Firmum y Ricina, había concluido, con razón, que las multas podian ser, en principio, establecidas en favor de cualquier comunidad ${ }^{101}$. $\mathrm{Si}$, a pesar de ello, en casi todos los casos las comunidades beneficiarias coincidian con aquellas en cuyos territorios se encontraba la tumba de referencia, no seria por razones juridicas sino más bien oportunistas, en el sentido de que, de la cercanía de la comunidad beneficiaria, cabía esperar una salvaguarda más eficaz de las disposiciones sepulcrales. En favor de esa interpretación aboga también el hecho de que, en los casos conocidos de excepción frente a la norma, son siempre comunidades vecinas las que se establecen como perceptoras ${ }^{102}$.

100 En lo esencial, lo mismo valdría para las inscripciones griegas. STEMLER, H. (Die griechischen Grabinschriften Kleinasiens, Halle $1909,67-68$ y $\mathrm{n}$. 98) cita algunos casos en los que hay una gran distancia entre el lugar de hallazgo del epígrafe y la comunidad beneficiaria, o bien se han encontrado en un mismo lugar inscripciones con distintas comunidades como beneficiarias.

101 Strafrecht 818 y n. 6. Un caso similar es el de CIL X 3594, de Misenum, inscripción funeraria de un miembro de la flota misenia y su familia, en la que se designa como beneficiario de la cuantia de la pena a la res p(ublica) de la vecina Puteoli. Cf. CIL X 3750 (Atella - Puteoli).

${ }_{102}$ Con las debidas reservas, resulta comparable una serie de inscripciones de Nicomedia (IGR III 11, con otros ejemplos), a tenor de cuyas estipulaciones las penas sepulcrales serían pagaderas al fiscus, a la ciudad (Nicomedia) y a sendas aldeas, situadas en el territorio de la ciudad (probablemente los lugares de origen de los difuntos). 
En el caso concreto de nuestra inscripción, ello significa que existe a priori una gran probabilidad de que la tumba se encontrara en el territorium de Aiungi, pero que tampoco hay que descartar la posibilidad de que el locus hubiera pertenecido a otra ciudad, y Aiungi sólo estuviera en su vecindad. Ahora bien, ¿en la vecindad de qué ciudad? Desde la convincente reconstrucción de Hübner de la línea que menciona el nombre de la ciudad (transmitida por copistas de los siglos XVI y XVII) en la desaparecida inscripción CIL II $1721^{103}$ como municipii Flavi Sosontigitanorum, se localiza unánimemente el antiguo Sosontigi en Alcaudete ${ }^{104}$; recientes hallazgos, como la ya mencionada inscripción de una Sosontigitana, aparecida en el cerro de la Almanzora, a $8 \mathrm{~km}$ al suroeste de Alcaudete ${ }^{105}$, o la inscripción votiva de un pont(ifex) municipi Sosontigitani, de Iponoba, localizada a $20 \mathrm{~km}$ al oeste de la misma ciudad ${ }^{106}$, aseguran la localización en la zona. Su ubicación exacta se basa, sin embargo, en el lugar de hallazgo de CIL II 1721 y en el mensaje del epígrafe. De acuerdo con las descripciones y dibujos conservados, se trata de un pedestal de estatua en cuya inscripción el Augustalis perpetuus Q.Valerius Optatus manifestaba que el ordo de Sosontigi había decretado cenae publicae en su honor, y le había asignado un lugar para la erección de una estatua suya y otras tantas de su mujer y de sus hijos, donde, en efecto, Optatus habia procedido a colocarlas. Por consiguiente, la tal inscripción correspondía al pedestal de la estatua de Optatus, que, junto con el pedestal o los pedestales de las de su mujer y sus hijos, dotadas de las correspondientes inscripciones, fue colocado en un lugar público de la ciudad. En Hispania ${ }^{107}$ puede tomarse como regla que un decreto del consejo de los decuriones registrado en el pedestal de una estatua, relativo a la erección de una estatua honorifica a una persona en vida (con independencia de la forma de

\footnotetext{
$103=$ ILS 5492. El texto transmitido es MVNICIPII FRAVASOSONLIGITANORVM, es decir, FLAVI SOSON•EGLITANORVM.

104 No andaba muy descaminado HüBnER al identificar ese Sosontigi con el Sosintigi (según emendación de DETLEFSEN; sobre el doblete Sosontigi/Sosintigi, vide cap. II) mencionado por Plinio ( NH 3,14) entre los oppida non ignobilia de la Baeturia túrdula. No puede caber ya, sin embargo, ninguna duda razonable de que Plinio ha cometido aquí un error (inversamente, sitúa el Baedro de Los Pedroches, o sea, de la Baeturia túrdula, entre el mar y el Guadalquivir, es decir, en la Bastetania). Contra cualquier intento de defender la localización de Plinio, o de postular un segundo Sosontigi/Sosintigi en el norte de la provincia de Córdoba, vide últimamente StYLow, A.U., CIL II $2 / 7$, Praefatio, XVI s.

105 ReCio (o.c. supra, n. 21) 39-42 no 56.

$106 \mathrm{AE} \mathrm{1983,536.}$

107 En la Italia septentrional ha podido identificar W. Eck (según nos ha comunicado amablemente), algunos pedestales de estatuas honoríficas, que fueron manifiestamente erigidas en fundi privados, no en la ciudad.
} 
financiación), o bien, como aquí, a la adjudicación de un lugar público para la colocación de una estatua a un conciudadano benemérito, aunque no fuera apto para la curia ${ }^{108}$, es uno de los criterios epigráficos más seguros para la localización del centro urbano - como algo diferenciado del territorium- de una ciudad privilegiada ${ }^{109}$. Por ello, el lugar de hallazgo de ese pedestal debería señalarnos el solar de la antigua Sosontigi.

Los copistas más antiguos, de mediados del s. XVI, vieron ya el pedestal junto al castillo de Alcaudete, pero A. de Morales ${ }^{110}$ sabía, además, que habia sido "traido de un despoblado media legua de alli»; medio siglo después precisaba el historiador local $M$. Jimena Jurado ${ }^{111}$ «traida de las ruinas de una poblacion grande que avia al pie de la sierra de Ayllo, una legua de Alcaudete". Las ruinas de donde procedía el pedestal se encontraban, pues, a 2-3 km ${ }^{112}$ del pueblo, al pie del Ahillo (así el nombre actual), y, en efecto, se encuentra alli, inmediatamente al este y por encima de la carretera de Las Casillas, un vasto asentamiento ibérico con restos romanos, hasta ahora no investigado, mientras que en el borde oriental de Alcaudete tendriamos una gran necrópolis romana, que hace pocos años se vio afectada por la urbanización del terreno situado al norte del Club Deportivo, y la consiguiente construcción de viviendas, siendo entonces destruida sin documentación arqueológica ${ }^{113}$. Así las cosas, no puede existir ninguna duda, de acuerdo con los criterios mencionados, sobre la localización de Sosontigi al nordeste de Alcaudete.

108 A juzgar por el cargo, cognomen y privilegio, Optatus era un liberto.

109 Eso no vale cuando tales decretos honoríficos se mencionan en inscripciones funerarias, según se ha señalado repetidamente (Stylow, A. U.: XVII Congr. Nac. Arq. [1983], Zaragoza 1985, 661; Gerión 3, 1985, 336; MDAl[M] 28, 1987, 94-95); con toda la claridad deseable lo indican dos inscripciones de duoviri de la Colonia Patricia, encontrada una de ellas (con huic ordo decrevit locum sepulturae, funeris impensam, statuam) en Carbula, ciudad vecina de Corduba (AE $1988,755=\mathrm{CIL} \|^{2} / 7,730$ ) y la otra (con locus sepulturae, funeris inpensa, laudatio, statua), a más de $80 \mathrm{~km}$ de Córdoba, en el territorium de Cisimbrium (HEp 1, 1989, 273). Sobre los criterios de identificación de las comunidades privilegiadas en Hispania, véase ALFöLY, G., Römisches Städtewesen auf der neukastilischen Hochebene. Ein Testfall für die Romanisierung, Heidelberg 1987, 27-30.

110 Las antigüedades de las ciudades de España que van nombradas en la Coronica .... Alcalá de Henares 1575 , f. 30 r.

111 Antigüedades del reino de Jaén, ms. Baeza 1639 (Bibl. Nac. Madrid., sign. 1180), f. 37 r.

112 La antigua legua hispana corresponde a una hora de camino, por lo que su longitud es variable.

113 La población parece que se extendía desde los cerros de la Celada y Los Santos hasta el parque y el polideportivo, donde está la gran necrópolis romana, que continúa por buena parte del pueblo actual. Cf. A. Rivas Morales, Historia de Alcaudete, Granada 1992, 19-20. Del polideportivo proceden la ya mencionada inscripción CILA Jaén 645 y otro fragmento de estela, asi como un altar funerario con un epigrafe casi totalmente borrado. La excavación de urgencia realizada en el patio del edificio, inmediatamente colindante por el oeste, del Instituto Nacional de Bachillerato 
¿Cómo concuerda con eso la mención de la res publica Aiungitanorum en el epigrafe funerario erigido a unos $3 \mathrm{~km}$ de Sosontigi? La posibilidad de que Aiungi hubiera sido una ciudad dependiente del territorio de Sosontigi se debe excluir por varias razones. A parte de la, en tal caso problemática, mención de una res publica propia, aboga en contra de tal hipótesis el hecho de que, en todas las inscripciones latinas pertinentes, la comunidad que debe recibir el dinero de las penas sea o un municipio 0 una colonia. Por otra parte, no se conoce hasta ahora ningún caso en la Hispania del s. II de una mención de origo perteneciente a una ciudad no privilegiada. En fin, y, por si lo anterior no fuera suficiente, tenemos la noticia, mencionada más arriba, del concilio de Elvira: si, como hemos argumentado, la Aiungi de nuestro epigrafe es la Adiungi del acta conciliar, tendríamos aquí una confirmación de su status de ciudad privilegiada, puesto que sabemos lo tenían todas las que se pueden reconocer en esa lista.

Aiungi era, pues, un municipio independiente. Aunque no se puede descartar del todo que su territorio llegara casi hasta las puertas de Sosontigi, y quedara incluida en él la zona de la finca "El Estanquillo", sin embargo, por razones topográficas, habría que suponer más bien que una gran parte del terreno que, desde el collado comprendido entre la imponente pirámide rocosa del Aillo $(1455 \mathrm{~m})$, esa atalaya que domina toda la zona hasta bien entrada la provincia de Córdoba, y la sierra de Orbes, situada delante - el collado sobre el que se asientan la antigua Sosontigi y la actual Alcaudete-, forma hacia el sur un suave declive hasta el río San Juan y cae en forma más abrupta hacia el norte hasta el río Víboras, pertenecia al territorio de Sosontigi. Ahora bien, el hecho de que Fabia Albana, tal vez casada con un sosontigitano y habitante de esta ciudad vecina bajo la condición de incola, hubiera intentado asegurar la inviolabilidad de su tumba por medio de una pena a cobrar por su ciudad de origen, resultaría, si, además hubiera carecido de descendencia, fácilmente comprensible.

Aiungi se encontraba, con seguridad, en las proximidades de Sosontigi. Dos significativos y hasta ahora anónimos oppida ibero-romanos, distantes ambos de Alcaudete unos $8 \mathrm{~km}$ a vuelo de pájaro, se prestarían a la iden-

\footnotetext{
"Príncipe Felipe" (HORNOS MATA, F. et al., AAA 1985, Sevilla 1987, III 206-209) no ha proporcionado ningún indicio claro de si se trata solamente de una villa rústica, o bien de un asentamiento grande. Sobre la extensa planta de la villa de Fuente Peña, entre el sur y el sudeste de Alcaudete (con materiales de los ss. I-V), véase Choclan Sabina, C. - Risouez Cuenca, C., AAA 1987, Sevilla 1990, III, 379-383.
} 
tificación: entre el oeste y el suroeste, el ya reiteradamente mencionado Cerro de la Almanzora (Luque, Córdoba), situado por encima de la orilla occidental del río Salado, y donde han aparecido, además de monedas y cerámica, cinco inscripciones, entre ellas el epígrafe funerario de una Ipolcobulculensis ${ }^{114}$, al igual que la mencionada Sosontigitana ${ }^{115}$; entre el este y el sudeste, el cerro Cabeza Baja con el oppidum de Encina Hermosa (Castillo de Locubín, Jaén) ${ }^{116}$. De todas formas, esos lugares no son los únicos candidatos, pues en el territorio limitrofe meridional de las provincias de Jaén y Córdoba, sólo unos pocos de los numerosos yacimientos urbanos conocidos han sido identificados con más o menos seguridad, mientras que, por otro lado, existe un gran número de topónimos atestiguados epigráficamente -en su mayoria claramente municipiossin localizar (véase el mapa, fig. 1) ${ }^{117 .}$

Identificados con seguridad están Iponoba, en el cerro del Minguillar, al sudeste de Baena (Córdoba), a $20 \mathrm{~km}$ entre el oeste y el noroeste de Alcaudete ${ }^{118}$; Ipolcobulcola, en Carcabuey (Córdoba) ${ }^{119}$; Iliturgicola, en el cerro Las Cabezas, al este de Fuente Tójar (Córdoba), a $10 \mathrm{~km}$ entre el sur y el suroeste de Alcaudete ${ }^{120}$; y también, al norte de esta localidad (a unos $18 \mathrm{~km}$ a vuelo de pájaro), la gran Colonia Augusta Gemella Tucci, en Martos, en el borde septentrional del sistema Subbético ${ }^{121}$.

114 AE 1915, 10.

115 REClO o.c. (supra, n. 21) 39-42 n 56. Las tres restantes inscripciones: HEp 4, 1994, 312 , el grafito mencionado por REcio (ibid. $48, n^{\circ} 70$, y véanse pp. $46-49$ sobre otros hallazgos cerámicos) y el tragmento de una inscripción paleocristiana (HEp 4, 1994, 310). Sobre el oppidum, véase Fortea PÉREz, J. - Bernier LuQue, J. Recintos y fortificaciones ibéricos en Córdoba y Jaén, Córdoba 1981, 55 ss., no 34 y VAquerizo Gil, D., AAA 1986, Sevilla 1987, II 91. Según VilLARONGA 1 Gafriga, L. (Corpus Nummum Hispaniae ante Augusti aetatem, Madrid 1994, 365) han sido halladas en la finca "El Salobral», a la que pertenece también el Cerro de la Almanzora, numerosas monedas (comienzos del s. II a.C.) de la ciudad de IPORA, hasta ahora no localizada.

116 Sobre esos hallazgos, véase Romero de TORRES, E. (Don Lope de Sosa 3, 1915, 216 220), quien pretendia localizar, sin fundamento, en ese lugar, Ipolcobulcula. Véase también REcio o.c. 49-50, no 76-79 y Hornos Mata, F. el al., AAA 1986, Sevilla 1987, III 203-209.

117 Sobre el territorio situado en la provincia de Córdoba, cf. STYLow 1983, 267-303, con el mapa de la p. 277.

138 STYLOW ibid. 278 ss.

119 Strlow ibid. 273 ss.

120 A pesar de las dudas manifestadas en otro tiempo (STYLow ibid. 279), entendemos ahora que, a la vista de CIL II 1648 y 1650, no se puede dudar de esa identificación. El hallazgo de HEP $1,1989,263$ confirma el status municipal. Un fragmento inédito de una tábula de bronce procede posiblemente de la copia local de la lex Flavia municipalis. La tribus Galeria del duumvir de CIL II 1648 (cf. WIEGELS, R., Die Tribusinschriften des römischen Hispanien. Berlín 1985, 40 s.) no descarta necesariamente una promoción a ciudad privilegiada en época flavia.

121 Vide CIL II p. 221; CILA Jaén p. 467-471. 
Una pena sepulcral en favor de la res publica Aiungitanorum

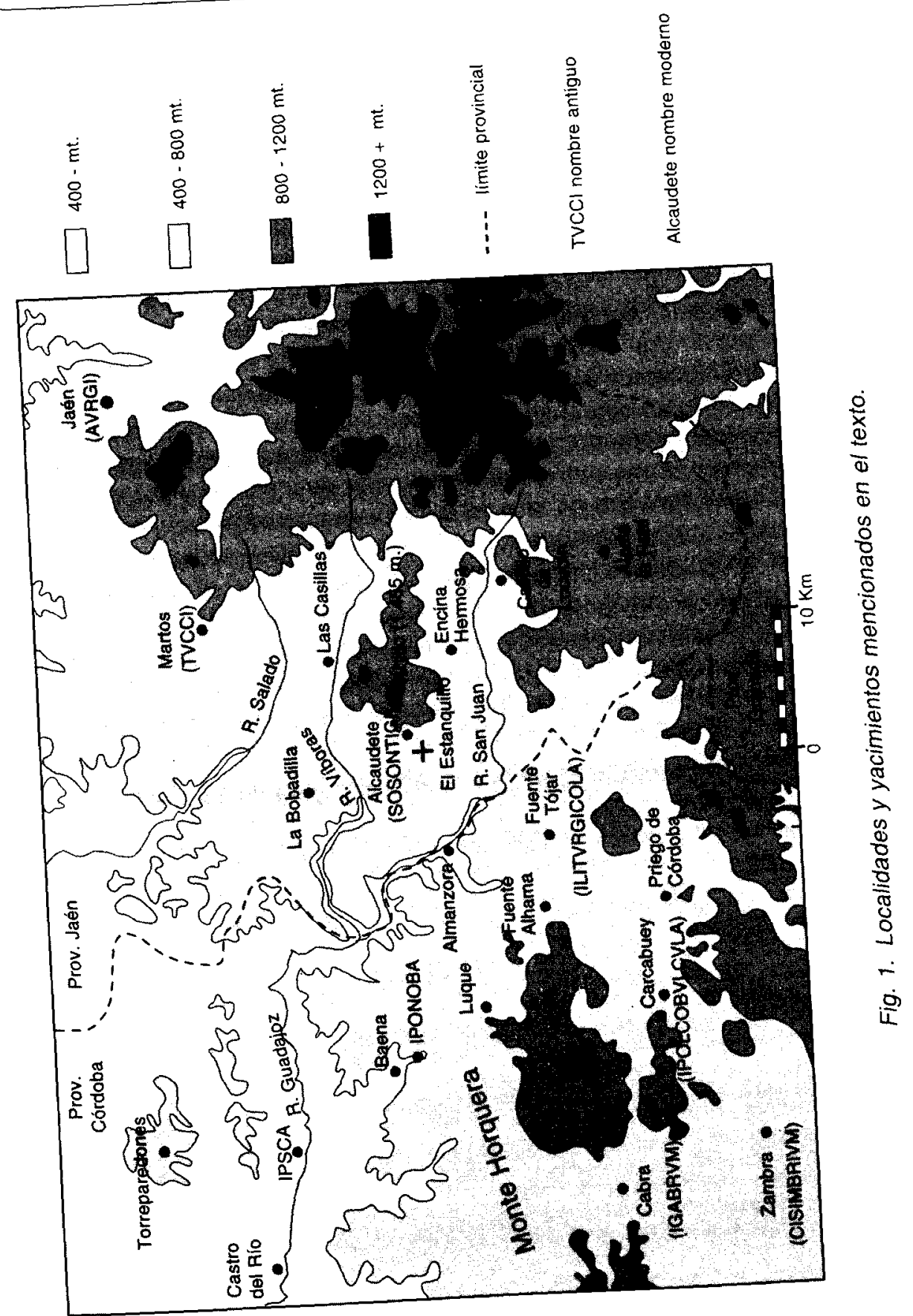


Entre las ciudades no identificadas, destaca con catorce inscripciones ${ }^{122}$ el municipium [---]nense (CIL II 1645) de Alcalá la Real, situado a $20 \mathrm{~km}$ a vuelo de pájaro al sudeste de Alcaudete. Mientras Hübner emendó [Ipolcobulco] $]^{\prime}$ Tense en CIL II 1645, A. Fernandez Guerra quería suplir aquí [Oelu]nense ${ }^{123}$, basándose en la mención de origo del epigrafe funerario CIL II 5467, procedente de las proximidades de La Bobadilla (un importante asentamiento antiguo, sito a $8 \mathrm{~km}$ al norte de Alcaudete); sin embargo, en lugar del L MARIVS MARVLLINVS OELVNENSIS que se nos ha transmitido, es mejor entender —con la filiación pospuesta- $\ulcorner Q$ (uinti) f(ilius) ${ }^{7}$ Lunensis. Aunque no la única imaginable, muni[cipium Lu]nense sería de hecho una reconstrucción muy aceptable para CIL $\|$ 1645, toda vez que los Lunenses están atestiguados ya una vez en Alcalá la Real: en la inscripción funeraria CIL II 1646 -bastante atípica- que dedican ellos ex decreto decurio(num), junto con el ordo municipii Polconens[is] y con los Dumienses ${ }^{124}$ ex decreto decurionum al duumvir (de Polco) $P$. lunius Avitus, donde el hecho de que los Lunenses aparezcan mencionados en último lugar, podría significar que la tumba del benemérito ciudadano de Polco se encontraba en su comunidad ${ }^{125}$.

El municipium Polconense sólo lo tenemos mencionado en esa inscripción. En la línea 2, se podría separar también municipi Ipolconens[is], con lo cual el nombre correspondería a un tipo corriente de topónimos ibéricos ${ }^{126}$, pero Polcone( $n)$ sis está documentado ya una vez en la línea 8 de la inscripción, por lo cual habría que quedarse provisionalmente con esta forma.

También los Dumienses, otro municipio, como se deduce de la mención de los decuriones, son por lo demás desconocidos, a no ser que se siga la propuesta de Mommsen, en el sentido de atetizar la primera parte de la mención de origo EST-ITLEDVNENSIS (así la mejor tradición) de la ins-

122 Casi todas en CILA Jaén 1-15.

123 Igualmente STYLOW 1983, 278 y n. 24.

124 HüBNER leyó en el manuscrito del Anónimo del s. XVII, que es el único que transmite la inscripción, PVMIENSES, pero la primera letra - corregida en el manuscrito- parece más bien una $D$.

125 Provisionalmente, debe permanecer abierta la cuestión de si guarda relación con el nombre de los Lunenses la consagración a Luna procedente del cercano Castillo de Locubín (CIL II 2092=5509), una de las cuatro que tenemos en Hispania -las otras son CIL II 3716, de Menorca, CIL II 4458, de Isona, y, finalmente, una de Málaga (Rodriguez OLiva, P., Jábega 21, 1978, 49-53); ILER 6779 es totalmente incierta; juntamente con Sol, aparece en CIL II 258 y $259+$ add., y, con una pluralidad de divinidades, en CIL II 2407.

$126 C f$., al lado de los numerosos topónimos en lpo-, sobre todo. Ipolcobulcula (el nombre que, según la suposición de Hübner, habria figurado realmente en la inscripción), un compuesto de Ipolco y Obulco (incluso el diminutivo Obulcula está atestiguado como topónimo cerca de La Luisiana, Sevilla). Por otro lado, se conocen dobletes con y sin i inicial, respectivamente, para poblaciones en cualquier caso diferentes, como p.e. Tucci (Martos) e Ituci (¿Torreparedones?, Baena). 
cripción CIL II 1601 de Fuente Alhama (Luque, a $7 \mathrm{~km}$ al oeste de Fuente Tójar), como una fórmula s(it) t(ibi) t(erra) /(evis) introducida en un lugar falso, de donde resultaría un nombre de ciudad Dun(i)enses, o bien Dum(i)enses.

Para la localización de la Sucaelo mencionada por Plinio ( $\mathrm{NH} \mathrm{3,10)}$ entre los celeberrima oppida situados entre el Betis y el mar, es decir, en la Bastetania, y, presumiblemente, en el conventus Astigitanus, tampoco permite precisión alguna la mención domo Sucaeloni del epígrafe $\mathrm{AE}$ 1935,6 , que un ciudadano y duumvir cordubense dedicó a su hija en lliturgicola ${ }^{127}$.

Dos municipios se mencionan en una inscripción encontrada al oeste de Alcalá la Real ${ }^{128}$, según la cual un sevir lpolcobulcule(n)sis APVEACLESIS (según otra versión, $A I V \bullet E A C L E S / S$ ) incola costeó estatuas en honor de Antonino Pío y sus hijos. Mientras que, debido al diferente sufijo, no se puede poner en relación con Aiungi el nombre de la ciudad donde vivía como incola el ciudadano de lpolcobulcula, y donde recibió los honores del sevirato, probablemente por la reparación del abastecimiento de aguas, no se puede descartar del todo, sin embargo, que en el lugar corrupto se esconda un lliturgic(o)le(n)sis. Hay que dejar de lado, en cualquier caso, la mención de origo Agul(ensis?) de la inscripción CIL II 1657 de Carcabuey (Ipolcobulcula), que, por su parte, deriva, con una cierta verosimilitud, de la ciudad de Agla Minor, mencionada por Plinio $(\mathrm{NH} 3,10)$, pero aún no localizada ${ }^{129}$.

Debemos seguir preguntándonos si los múltiples hallazgos realizados cerca de Las Casillas ${ }^{130}$, a $9 \mathrm{~km}$ al nordeste de Alcaudete, permiten o no situar allí una ciudad de nombre Bora, por lo demás desconocida, y si esa supuesta ciudad siguió existiendo durante la época imperial como comunidad independiente.

127 Sobre todo no permite situar Sucaelo en el cerro Las Cabezas, tal y como suponía DE Navascues $Y$ de Juan, J.M. (Anuar. Cuerpo Fac. Arch. Bibl. Arq. 1, 1934, 334 ss.), basándose en la inscripción.

${ }_{128}$ CIL II 1643. Los datos del viajero veneciano B. Ramberto (mediados del s. XVI), que es el único que transmite la inscripción - en el camino de Pliego [ahora Priego de Córdoba] ad Alcalá, media legua al Pozzo del Torcon"- no permiten ninguna localización exacta, puesto que ya no se sabe dónde estaba el "Pozzo del Torcon".

${ }_{129}$ Ya lo suponia DETLEFSEN, D. (“Die geographie der provinz Baetica bei Plinius (NH III, 617)", Philologus 30, 1870, 290 (cf. HüBneR, CIL \| p. 872). La misma origo, quizá, en CIL II 1658.

130 VILLARONGA o.c. (supra n. 115) 364; correspondientes a la primera mitad del s. II a.C. No queda claro, por desgracia, si la zona de los hallazgos debe identificarse con el asentamiento romano situado a unos $5 \mathrm{~km}$ al oeste de Las Casillas, en la ladera occidental del cortijo Camposolo y del cortijo Almendro, que Montilla PÉrez, S. (AAA 1986, Sevilla 1987, II 146-147) enumera entre los más significativos del término municipal de Alcaudete. 
Finalmente, hay que mencionar la designación de origo Siccaenas de la ya citada estela funeraria CIL II 1598 del Monte Horquera, al oeste de Iponoba, que, con gran probabilidad, se relaciona con una ciudad de esa zona, de la que no conocemos ni la ubicación ni el nombre exacto ${ }^{131}$.

Por consiguiente, ciñéndonos a los nombres conocidos hasta ahora, resulta que se apiñan aquí, en un espacio reducido - un territorio de una extensión aproximada de $35 \mathrm{~km}$ este-oeste y $20 \mathrm{~km}$ norte-sur-, una docena larga de ciudades. Distantes, la mayoría de las veces, menos de $15 \mathrm{~km}$ de sus vecinos, y a menudo situados al alcance de su vista, esos centros urbanos, a veces minúsculos, $y$, como herederos que eran de un turbulento pasado, instalados en mesetas y cerros de fácil defensa, ocupaban territorios que en muchos casos no deben de haber sobrepasado los $50 \mathrm{~km}^{2}$. De éstos, sólo una pequeña parte era tierra cultivable, el resto, roca y karst; en cuanto a los arroyos y ríos, un tanto caudalosos. debido a la relativamente alta pluviosidad, sólo se podían utilizar para el abastecimiento de aguas y el riego en forma limitada, ya que tenian, en parte, una fuerte salinidad. La razón de la fragmentación política es, sin duda, la naturaleza del terreno, que, en el accidentado sistema Subbético ${ }^{132}$, únicamente deja espacio para pequeños o minúsculos lugares de asentamiento, en algunos casos comunicados entre sí sólo por puertos y desfiladeros.

A pesar de ello, y eso es lo auténticamente asombroso, disponían, como se ve por las inscripciones ${ }^{133}$, esas ciudades - suponemos que, sin excepción, elevadas al rango de municipios de derecho latino por los Flavios- de instituciones políticas y de una estructura urbana en nada diferente, excepto en tamaño, de la que conocemos de otras ciudades ro-

131 HüBNEa pensó en Siccaena o Siccaenum, pero la cuestión sigue incierta, en razón de ese sufijo totalmente desacostumbrado en la zona. Vèase tambièn WiEGELS o.c. (supra, n. 120) $45 \mathrm{n}$. 1 (quien trataba de poner en relación la tribus Galeria del difunto con la ciudad de Torreparedones [ituci?], lo que es totalmente inverosímil, por razones geográficas).

132 Lopez Ontiveros, A. ("Relieve y morfología”, en Córdoba y su provincia, Sevilla 1985, I, 45) señala que el relieve de la zona es uno de los que tienen mayor complejidad y complicación de toda la Peninsula.

133 Excavaciones arqueológicas en centros urbanos sólo se han realizado hasta ahora en Iponoba (MuÑoz AmilibiA, A.M., "Excavaciones en el Cerro del Minguillar de Baena [Córdoba]", Instituto de Arqueologia y Prehistoria, Universidad de Barcelona, Memoria 1975, 15-16; EADEM, "Excavaciones de Iponoba. Novedades arqueológicas", en Segovia. Symposium de arqueologia romana, Barcelona 1977, 279-283) e Iliturgicola (VAQUerizo GIL, D. - Murillo Redondo, J.F. Quesada Sanz, F., Anales de Arqueologia Cordobesa 3, 1992, 171-197; IDEM, Arqueologia cordobesa. Fuente Tójar [Córdba], Córdoba 1994), habiendo proporcionado, por lo demás, una información minima sobre la planta de esas ciudades. Sobre la posible existencia de un teatro en Iliturgicola, véase Leiva Briones, F., Iliturgicola n³ (Fuente Tójar, dic. 1991), p. 11. 
manas provinciales. Oímos hablar de foros y de templos ${ }^{134}$; por doquier están atestiguados el ordo decurionum, duumviri, pontifices, seviri, Augustales y esclavos públicos ${ }^{135}$; tienen sus copias en bronce de la lex Flavia municipalis ${ }^{136}$; el territorio de la comunidad está mensurado y amojonado ${ }^{137}$; emperadores y ciudadanos beneméritos reciben estatuas honoríficas con las fórmulas consabidas; existe la obligación social de costear ciertas obras en beneficio de la comunidad ${ }^{138}$; se ejecutan las disposiciones testamentarias de forma perfecta ${ }^{139}$; y hasta los epigramas funerarios repiten modelos conocidos ${ }^{140}$. En absoluto vivian las pequeñas comunidades aisladas de su entorno: la proximidad territorial daba lugar a un intenso intercambio de población, según pone de manifiesto el gran número de incolae atestiguados, quienes, llevados por una especie de orgullo de patria chica, mencionaban gustosamente su origen - convirtiendo con ello en una empresa casi desesperada para nosotros la identificación de las diferentes ciudades-, e, incluso, no era raro que los ordines de varias ciudades (acaso condicionados por estrecheces financieras) se pusieran de acuerdo para honrar conjuntamente a un ciudadano benemérito. Pero, sobre todo, son los omnipresentes Patricienses ${ }^{141}$ establecidos en la zona, o realizando en ella sus negocios, quienes atestiguan que, vistas desde Corduba, la capital de la provincia, esas ciudades podían estar lejos, pero desde luego no estaban fuera del mundo ${ }^{142}$.

Con ese trasfondo, pierde algo de su singularidad el testimonio, a primera vista tan sorprendente, de una pena sepulcral. Es probable que ese tipo de pena fuera de verdad un instrumento jurídico muy poco utilizado en Hispania, pero nuestra inscripción muestra que era manejado de una forma absolutamente normal, y debería servir de advertencia contra los argumentos ex silentio precipitados.

134 CIL II 1650 y 2098.

135 AE 1983, 534.

136 Cf. supra, n. 120. Irni, donde fueron halladas hace quince años las conocidas tábulas de bronce con la lex Irnitana, se encuentra situada a unos $100 \mathrm{~km}$ hacia el oeste, en una zona que se asemeja mucho a la que acabamos de describir.

;37 Vide AE 1986, 334c, sobre un terminus de Domiciano entre Cisimbrium e Ipolcobulcula, colocado por decisión del gobernador.

${ }_{138}$ Ex. gr. CIL II 1643 (abastecimiento de agua) y 1647 (epulo dato).

139 Cf. ex. gr. CIL II 1637, con un curator operis y dos arbitri.

140 Cf. AE 1985, 560.

141 AE 1935, 6 (lliturgicola), CIL II 1600 (Iponoba), HEp1, 1989, 273 (Cisimbrium), CIL II 1637, junto con una inscripción inédita (Ipolcobulcula) y CILA Jaén 645, sin reconocer la origo (Sosontigi).

142. Incluso un veterano de la flota ravenate, nacido en la lejana Pannonia, fijó su residencia, en el s. III, a $25 \mathrm{~km}$ de Alcaudete (CIL II2/7, 127a); posiblemente habia prestado servicio en un destacamento de la flota estacionado en el Estrecho. 